\title{
Convection-Climate Feedbacks in the ECHAM5 General Circulation Model: Evaluation of Cirrus Cloud Life Cycles with ISCCP Satellite Data from a Lagrangian Trajectory Perspective
}

\author{
SWATI GEHLOT* AND JOHANNES QUAAS ${ }^{+}$ \\ Max Planck Institute for Meteorology, Hamburg, Germany
}

(Manuscript received 21 June 2011, in final form 1 December 2011)

\begin{abstract}
A process-oriented climate model evaluation is presented, applying the International Satellite Cloud Climatology Project (ISCCP) simulator to pinpoint deficiencies related to the cloud processes in the ECHAM5 general circulation model. A Lagrangian trajectory analysis is performed to track the transitions of anvil cirrus originating from deep convective detrainment to cirrostratus and thin cirrus, comparing ISCCP observations and the ECHAM5 model. Trajectories of cloudy air parcels originating from deep convection are computed for both, the ISCCP observations and the model, over which the ISCCP joint histograms are used for analyzing the cirrus life cycle over 5 days. The cirrostratus and cirrus clouds originate from detrainment from deep convection decay and gradually thin out after the convective event over 3-4 days.

The effect of the convection-cirrus transitions in a warmer climate is analyzed in order to understand the climate feedbacks due to deep convective cloud transitions. An idealized climate change simulation is performed using a $+2-\mathrm{K}$ sea surface temperature (SST) perturbation. The Lagrangian trajectory analysis over perturbed climate suggests that more and thicker cirrostratus and cirrus clouds occur in the warmer climate compared to the present-day climate. Stronger convection is noticed in the perturbed climate, which leads to an increased precipitation, especially on day -2 and -3 after the individual convective events. The shortwave and the longwave cloud forcings both increase in the warmer climate, with an increase of net cloud radiative forcing (NCRF), leading to an overall positive feedback of the increased cirrostratus and cirrus clouds from a Lagrangian transition perspective.
\end{abstract}

\section{Introduction}

Feedbacks in the climate system associated with clouds continue to be considered a major source of uncertainty in model projections of global warming (Stephens 2005; Solomon et al. 2007). In particular, the tropics are associated with a large spectrum of cloud types, ranging from boundary layer clouds to deep convective clouds and anvils. Because of their different top altitudes and optical properties, the different cloud types affect the Earth's

\footnotetext{
* Current affiliation: Institute for Oceanography, Universität Hamburg, Germany.

+ Current affiliation: Institute for Meteorology, Universität Leipzig, Germany.

Corresponding author address: Swati Gehlot, Institute for Oceanography, Universität Hamburg Bundesstrasse 53, Hamburg 20146, Germany.

E-mail: swati.gehlot@zmaw.de
}

radiation budget in various ways. Understanding cloud radiative feedbacks requires an understanding of how a change in climate may affect the distribution of the different cloud types and their radiative properties and an estimate of the impact of such changes on the Earth's radiation budget (Bony et al. 2006).

Because of the profound influence of clouds on both the water balance of the atmosphere and the Earth's radiation budget, small cloud variations can alter the climate response associated with various forcings of global change. Projections of global warming by general circulation models (GCMs) forced with prescribed increases of atmospheric $\mathrm{CO}_{2}$ are uncertain, and the range of uncertainty has, seemingly, not changed much from initial estimates given decades ago (Solomon et al. 2007). The effects of potential changes in cloudiness as a key factor in the problem of climate change has been recognized since at least the 1970s (Arakawa 1975; Schneider 1972).

For more than a decade, the large spread of cloud feedbacks among climate models has been considered 
a major source of uncertainty for climate sensitivity estimates (Cess et al. 1990; Colman 2003; Stephens 2005). The representation of convective and boundary layer processes, in addition to the parameterization of cloud properties, is known to be critical for the prediction of the clouds' response to climate change (Senior and Mitchell 1993; Yao and Genio 1999), and it differs widely among models as seen in various model intercomparison studies.

Several climate feedback mechanisms involving convective clouds have been examined with observations, climate models, and cloud-resolving models in the past. Tropical cirrus clouds (or ice-phase clouds in the upper troposphere) have a substantial large-scale radiative effect on the Earth's climate system (Hartmann and Michelsen 1993). Between $20 \%$ and $45 \%$ of the global tropics are regularly covered by extensive cirrus systems (Liou 1986; Stubenrauch et al. 2006). On the one hand, the cirrus clouds reduce the solar radiation reaching the Earth's surface because of reflection and scattering making it cooler, while on the other hand these cloud layers also absorb a portion of the upwelling terrestrial infrared (IR) radiation, heating the surface and atmosphere (Ackerman et al. 1988). The net radiative effect of tropical cirrus depends on many factors such as the properties of the underlying surface and the atmosphere (Stephens et al. 1990), the cloud-top height and thickness, ice water content, and the ice crystal size distribution (Stephens 2005).

Cirrus and cirrostratus clouds in the tropics have strong connections with deep convective clouds. In the tropics, the primary moisture source for cirrus clouds formation is attributed to deep convective cloud detrainment in the upper troposphere. The cirrus cloud formation is further influenced by interplay of largescale atmospheric dynamics and the deep convection source (Chou and Neelin 1999). Cirrus clouds generated by deep convection are maintained through dynamical or radiative processes over times much longer than the lifetime of individual cirrus clouds (Pfister et al. 2001; Massie et al. 2002; Luo and Rossow 2004; Mace et al. 2006). Owing to the range of acting dynamical and microphysical mechanisms, our knowledge about the distribution of tropical cirrus, their variability, and formationdecay processes is still rudimentary (Luo and Rossow 2004).

The findings by May et al. (2008) reveal that the fresh thunderstorm anvil cirrus show the presence of platelike, irregular ice crystals, whereas the aged anvils showed predominantly bullet rosettes or aggregates of bullet rosettes. The difference in crystal structures between the fresh and aged anvils (or, the closer and farther cirrus from the convective centers) gives information about the formation mechanisms. The ice crystal structure analysis presented by May et al. (2008) shows that the irregular, quasi-spherical ice particles contributed to the total mass and optical properties of the fresh cirrus, and the dominant bullet rosette ice crystals in the aged anvil cirrus cloud signify that new particle formation is occurring in regenerating cells over time and space.

While field campaigns like Cirrus Regional Study of Tropical Anvils and Cirrus Layers-Florida-Area Cirrus Experiment (CRYSTAL-FACE) (Garrett et al. 2005) and Tropical Warm Pool-International Cloud Experiment (TWP-ICE) (May et al. 2008)—specifically dedicated to investigating properties of parent convective systems and the resultant cirrus clouds-are very useful, they tend to be limited in their spatial as well as temporal extent, which makes it difficult to generalize their findings into an understanding of cirrus formation evolution and dissipation processes at a global scale. Satellite observations collected in the past decades have produced cloud climatology long enough to provide a global overview of cloud properties in several temporal and spatial scales. Machado and Rossow (1993) used satellite imagery to examine the properties of tropical convective cloud systems. During the mature stage, Machado and Rossow (1993) determined that an average tropical convective system consists of $20 \%$ deep convective clouds, $28 \%$ transition anvil cloud, and $52 \%$ cirrus anvil cloud. During the dissipating stages, first the deep convective clouds disappear, then they transition to anvil clouds, leaving finally only scattered fragments of thin cirrus. Additionally, studies using satellite data trajectories for tracking the upper-tropospheric water vapor (Salathe and Hartmann 1997; Soden 1998, 2004; Horváth and Soden 2008) and cirrus formation and maintenance (Salathe and Hartmann 1997; Luo and Rossow 2004; Horváth and Soden 2008; Mace et al. 2006) have been carried out in the past. However, investigating the process-based interaction of deep convection and cirrus clouds in a framework of a GCM have not been attempted before. To characterize the life cycle and evolution processes of deep convection-generated cirrus within a GCM, we adopt the Lagrangian trajectory method developed and used by Luo and Rossow (2004) that tracks tropical cirrus systems by following upper-tropospheric air masses using reanalysis wind fields and extend their convection-cirrus cloud formation and maintenance life cycle study to a consistent analysis of the ECHAM5 atmospheric GCM and International Satellite Cloud Climatology Project (ISCCP) satellite data.

The organization of the paper is as follows. The details of the satellite observations are reported in section 2 along with the ECHAM5 general circulation model description 
and experimental setup. Section 3 gives a comparative overview for the global average geographical distribution of different types of cloud quantities for observations and model simulations. Section 4 describes an overview of the Lagrangian trajectory method and its application in the current work. Detailed comparison of the deep convection-cirrus transition in ISCCP observations as well as in the model-derived cloud fields are also shown in section 4 . Section 5 lists the details of the comparison of cirrus cloud transitions for the perturbed climate experiments to the present-day climate experiment in order to examine the climate feedback processes in a warmer climate. Finally, section 6 summarizes the results and examines them for their implications for cirrus modeling deficiencies in a stateof-the-art GCM-like ECHAM5 and provides some insight into convection-cirrus feedback from a sea surface temperature (SST) perturbation point of view.

\section{Description of observations and GCM}

Life cycle analysis of cirrus clouds as derived from the satellite observations as well as model cloud properties are presented in the following sections.

\section{a. ISCCP satellite data}

The ISCCP has been operational since 1983 (Schiffer and Rossow 1983). The ISCCP climatological data are created using radiance measurements from visible (VIS) and IR channels on up to five geostationary and two polar-orbiting satellites (Rossow et al. 1996). Surface soundings together with retrievals from the Television and Infrared Observation Satellite (TIROS) Operational Vertical Sounder (TOVS) system for temperature and moisture profiles are used as input to the cloud retrievals. The VIS channel is used to derive cloud optical thickness $(\tau)$, and the IR channel is used to derive cloudtop temperature and, hence, the cloud-top pressure $\left(p_{\text {top }}\right)$.

The ISCCP data retrieval analysis begins by classifying each individual satellite pixel, about 4-7 km in size, as either cloudy or clear (Rossow and Garder 1993). A pixel is defined cloudy if the IR or VIS radiance differs from the corresponding clear sky value by more than the detection threshold (more details explained in Rossow and Schiffer 1999). Clouds that produce radiance changes that are too small or of the wrong sign are not detected. The individual pixels are assumed to be completely cloud covered; hence, the fractional area cloud cover is determined only for larger areas (i.e., $280 \mathrm{~km}$ across or final regridded resolution of ISCCP D2 product) in the ISCCP datasets by the fraction of all pixels in each area containing clouds. The cloud cover values for these areas are determined by the total number of pixels collected; for

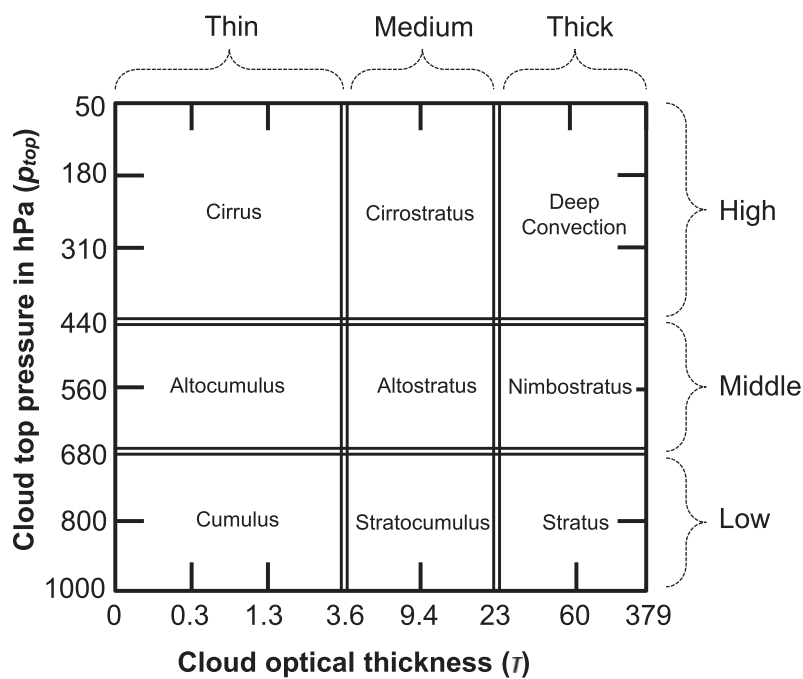

FIG. 1. ISCCP cloud classification based on the categories of cloud optical thickness ( $\tau$, defining the thickness) and cloud-top pressure ( $p_{\text {top }}$, defining the cloud height) joint histogram.

one particular sampling instant, this number ranges from 20 to 120 , with about 70 on average in a $280-\mathrm{km}^{2}$ grid. If an individual pixel is defined cloudy, then comparison of the observed radiances to those predicted by a radiative transfer model (Rossow and Schiffer 1991) determines a cloud-top temperature from the IR radiances (both day and night) and a visible optical thickness $(\tau)$ from the VIS radiance (daytime only). Retrieved cloud-top temperatures are translated to a pressure using the TOVS temperature profiles. An important characteristic of the cloud-top temperature retrieval is worth noticing in case of overlapping clouds. For example, the presence of a high, optically thin cloud above a low, optically thick one would result in the retrieval of a single-layer cloud in a middle level in the place of two overlapping cloud layers. In addition to this effect, any systematic biases in the TOVS temperature profiles would result in systematic errors in the ISCCP cloud-top pressures. More details on the ISCCP data retrieval are explained in Rossow and Schiffer (1991), Rossow et al. (1996), and Rossow and Schiffer (1999). Typical cloud types are essentially classified according to their top pressure and optical thickness as described in detail in Rossow and Schiffer (1999) as ISCCP cloud summary statistics. The ISCCP cloud classification schematic is shown in Fig. 1.

Summary statistics of six ranges of optical depth are defined for seven pressure ranges of cloud-top height. This distribution is also referred as ISCCP $p_{\text {top }}-\tau$ joint histogram. The composite of the top three bins of cloudtop pressure over all the bins of optical thickness represent the high cloud cover (HCC). Similarly, the next two bins and the last two bins of cloud-top pressure 
constitute the middle and low cloud cover (MCC and LCC, respectively). The ISCCP data sampling is done every $3 \mathrm{~h}$ (about four time steps in the daylight) and the spatial resolution at which the ISCCP joint histograms are produced is $280 \mathrm{~km} \times 280 \mathrm{~km}$. In the current work, the ISCCP D2 data for a winter and summer month for the year 2002 (January and July) are used.

\section{b. ECHAM5 model and experimental setup}

For the current study, the ECHAM atmospheric general circulation model is used. The climate model ECHAM5 (Roeckner et al. 2003) is the fifth-generation model developed from the spectral weather prediction model of the European Centre for Medium-Range Weather Forecast (ECMWF) and a comprehensive parameterization package developed at the Max Planck Institute for Meteorology, Hamburg.

The prognostic variables (i.e., temperature, vorticity, divergence, logarithm of the surface pressure, and the total water mixing ratio) are represented in the horizontal by a finite series of spherical harmonics. In the vertical, the atmosphere is divided into hybrid sigmapressure levels reaching up to the pressure level of $10 \mathrm{hPa}$ (Roeckner et al. 2003). Throughout this study we use the resolution T63L31. T63 denotes the truncation of the series of spherical harmonics at the zonal and total wavenumber of $63\left(\sim 1.9^{\circ} \times 1.9^{\circ}\right.$ spatial resolution on a corresponding latitude-longitude grid); L31 refers to the usage of 31 vertical levels.

The physical parameterizations within the ECHAM5 model consider longwave radiation, shortwave radiation, gravity wave drag, the planetary boundary layer, cumulus convection, stratiform cloud formation, and microphysics/precipitation formation. A bulk mass flux scheme including the effects of entrainment and detrainment on the updraft and downdraft convective mass fluxes is employed for shallow, midlevel, and deep convection based on Tiedtke (1989) with modifications for penetrative deep convection according to Nordeng (1994). Cloud microphysics based on Lohmann and Roeckner (1996) include a prognostic treatment of cloud ice representing the components of the atmospheric moisture budget in ECHAM5 and, hence, at each time step, model condensate is generated or evaporated depending on the current meteorological conditions, and sedimentation of ice is taken into account. Large-scale cloud cover and large-scale condensation/evaporation are predicted by a subgrid-scale variability scheme as described in Tompkins (2002). The cloud water at each model time step is consistent with the simulated largescale total water content and temperature, which are affected themselves by radiative cooling and large-scale dynamics, so that the relevant processes are accounted for in the generation, maintenance, or dissipation of cloud ice. For the vertical cloud overlap considerations, the maximumrandom overlap assumption is applied. The ECHAM5 model simulations are initialized using climatological SSTs.

The current work uses the ISCCP simulator (Klein and Jacob 1999) as a diagnostic tool for analyzing the model cloud properties and to make them directly comparable with the ISCCP satellite observations. The ISCCP simulator, as the name suggests, is a model-based simulator to mimic the satellite products as seen by the ISCCP retrievals. The primary motivation for the creation of the ISCCP simulator coupled with a GCM is the possibility to compare the model output one to one with the ISCCP satellite data. The simulator itself is a runtime diagnostic tool to analyze the model output by mimicking the satellite signals as computed from three basic model variables [i.e., cloud optical thickness $(\tau)$, cloud-top pressure ( $\left.p_{\text {top }}\right)$, and cloud fraction]. Hence, at every grid point in the model, account is taken of how a satellite would view an atmospheric column with profiles of gridbox mean physical properties of the model. The ISCCP simulator cloud data are produced by accounting for radiative characteristics of clouds to make the modeled cloud fields comparable to the ISCCP satellite data retrieval. The first is the identification of clouds by their tops since passive satellite sensors do not define the geometric thickness of clouds but rather the height of their tops. For example, if a high-level cloud overlies a low-level cloud, it will generally be identified as only a high-level cloud by a satellite. Second, the ISCCP retrieval algorithm may underestimate the altitude of clouds with partial emissivity, especially if the partially emissive cloud lies above an optically thick cloud. For example, only one cloud-top pressure, $p_{\text {top }}$, can be assigned by ISCCP to each satellite pixel, and in the case of multilayer clouds this is usually the $p_{\text {top }}$ of the highestlevel cloud or a radiatively weighted average in the case of thin clouds. Considering these two basic characteristics when accounting for the satellite observations ensures that the ISCCP simulator creates the same, radiatively defined cloud-top temperature as the ISCCP satellite retrievals leading to radiatively consistent cloud properties simulated from the model gridbox mean data.

At a coarser scale, the gridbox mean value is the cloud property averaged over all satellite pixels within the grid box. In sampling this subgrid-scale variability in the GCM, the model's vertical profile of cloud fraction and its overlap assumption are used to determine what fraction of the grid box is covered by clouds of a given range of $p_{\text {top }}$ and cloud optical depth $\tau$. Additionally, the ISCCP simulator used in the current work is modified to include a subcolumn sampler based on the work of Räisänen 
et al. (2004). The current version of the ISCCP simulator accounts for the subgrid-scale variability by using the horizontal probability density function of total water content and hence stochastically generating a number of either cloudy or clear subcolumns in each model grid box at all the levels. More details on the subcolumn sampler can be found in Räisänen et al. (2004).

The model output in the form of ISCCP summary statistics of cloud optical depth and cloud-top pressure (ISCCP $p_{\text {top }}-\tau$ joint histogram shown in Fig. 1) are used for evaluating the model with respect to the ISCCP observations and form the basis of this model evaluation study. The time period for the study is a winter and a summer month for year 2002 (January and July). In contrast to the ISCCP observations, which are retrieved only during the sunlit time of the day, the ISCCP simulator can be modified to obtain day-night data for cloud properties, ensuring a continuous time-resolved formationmaturation-decay behavior for various cloud quantities. The comparison of cloud quantities in ECHAM5 daytime (sunlit time steps) and the day-night simulations reflected no substantial difference (not shown). Hence, in the current work, the model-simulated ISCCP histograms are computed for day and night instances every $3 \mathrm{~h}$ for a continuous temporal resolution of cloud quantities, whereas the ISCCP observations exist only during the daytime at 3-h intervals and represent only the sunlit part of the day.

\section{Comparison of the global distribution of deep convective, cirrostratus, and cirrus clouds}

Following the ISCCP cloud classification (Fig. 1), the cirrus, cirrostratus, and deep convective clouds are compared with regard to their geographical distribution within the GCM and the ISCCP observations. The categorization of clouds is based on the thresholds of cloudtop pressure $\left(p_{\text {top }}\right)$ and cloud optical thickness $(\tau)$. The high cloud cover (sum of deep convective, cirrostratus, and cirrus clouds) distribution is also compared for the ISCCP observations and the model output.

Figure 2 shows the different cloud cover distributions for the monthly average of January 2002. The global average mean and the average mean values from latitudinal range of $\pm 50^{\circ}$ for tropically originating deep convective, cirrus, cirrostratus, and high clouds are listed in Table 1 for a quantitative comparison of cloud quantities for the ISCCP observations and the model. As seen in these geographical distributions, consistently in the observations and the model, the deep convective and cirrus clouds primarily populate the tropics. The mean cloud amount for deep convective clouds of tropical origin $\left( \pm 50^{\circ}\right.$ in the current study) is found comparatively larger
$(4.9 \%)$ in the model than in the ISCCP observations (3.6\%) with a visible overestimation over the continental land areas in the tropics. Since the deep convection is more easily triggered in the boundary layer over the continental tropics, this overestimation of tropically originated cirrus and the deep convective cloud amount leads to an overall larger high cloud cover in the model simulations (34.0\%) in comparison to the mean of tropically originating ISCCP high cloud cover $(23.9 \%)$. The tropically originating cirrus clouds are generally located in the regions of prominent convective activity where abundant moisture is available [the intertropical convergence zone (ITCZ), tropical Africa, the Amazon, and tropical warm pool, among others]. The cirrus geographical distribution in the tropics is similar in the observations and the model; however, the tropically originated cirrus cloud amount in the ECHAM5 model is considerably higher $(21.9 \%$, compared to $13.8 \%$ for observations). The amount of tropically originated cirrostratus clouds, which is also relatively large in the subtropics, is on an average slightly larger in the model $(7.2 \%)$ than in the observations $(6.5 \%)$, and too much centered in the inner tropics.

The comparison of geographical average mean values provides a first idea that the model cloud quantities are comparatively higher than in the ISCCP observations. The conclusions for the comparison of geographical distributions in July 2002 are very similar to those for January, and are thus not shown here. However, this comparison of average cloud quantities does not provide an insight into the cloud processes simulated in the model (the formation, maintenance, and decay of clouds). The evaluation of the model in terms of cloud life cycle processes (particularly the transition of deep convection to cirrus clouds) requires a more detailed process-based analysis of individual cloud quantities at different stages of their formation, maintenance, and decay, which is shown in subsequent sections.

\section{The Lagrangian forward trajectory analysis}

To analyze the transition of deep convective clouds to cirrus clouds, we use the Lagrangian forward trajectories to track the movement of deep convective air parcels in the observations and in the model output. The latitudinal extent of the global distributions is restricted to $\pm 50^{\circ} \mathrm{N}$ in order to characterize the behavior of cloud transitions of tropical origin. The extracted cloud properties over the upper-tropospheric wind trajectory path are analyzed to compute the daily average transition histograms for 5 consecutive days following a deep convective event. Adopting the idea by Luo and Rossow (2004), the primary hypothesis in the deep convectioncirrus transition is that a deep convective event is 
ISCCP January 2002 - DCC in \%

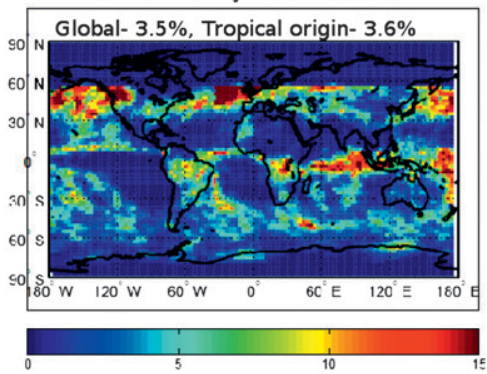

Model January 2002 - DCC in \%

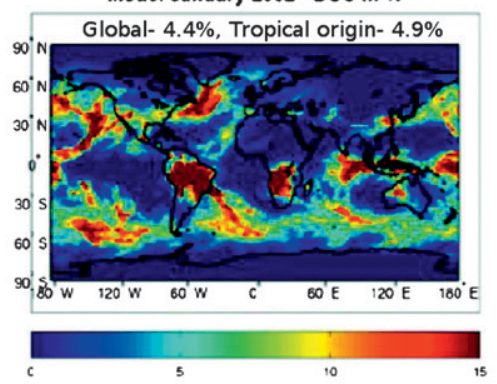

(a) ISCCP - Deep-convective cloud cover (b) Model - Deep-convective cloud cover

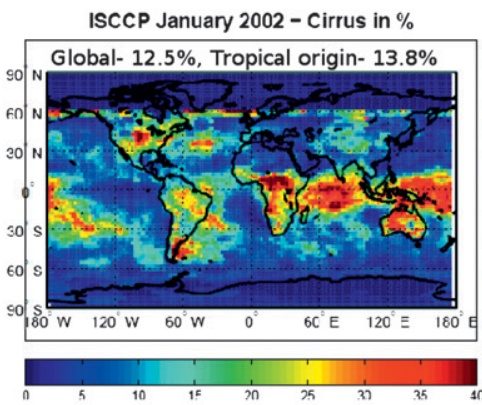

(c) ISCCP - Cirrus cloud cover

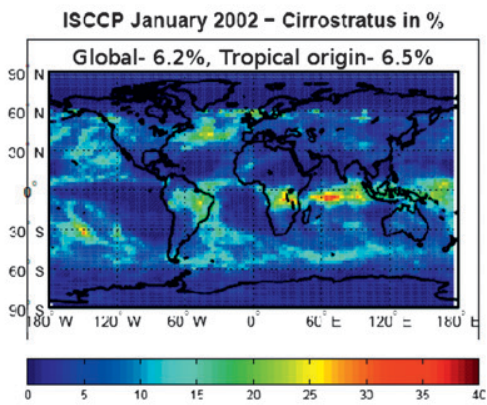

(e) ISCCP - Cirrostratus cloud cover

ISCCP January $2002-\mathrm{HCC}$ in \%

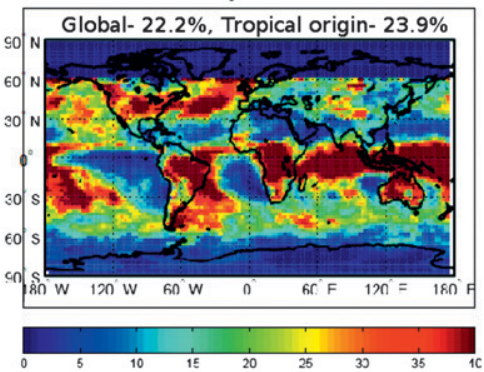

(g) ISCCP - High cloud cover ( $\mathrm{HCC})$
Model January 2002 - Cirrus in \%

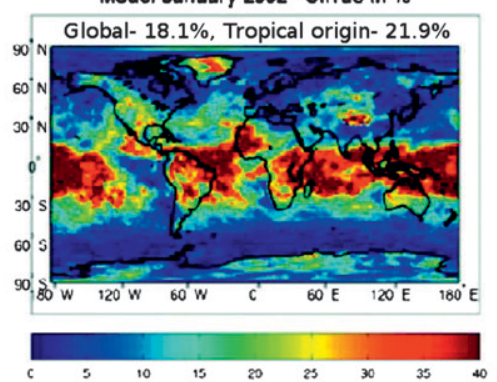

(d) Model - Cirrus cloud cover

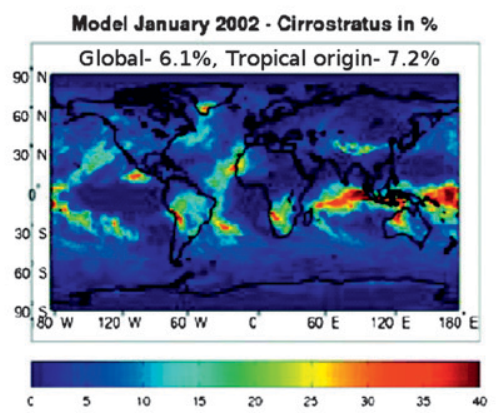

(f) Model - Cirrostratus cloud cover

Model Jenuary $2002 \cdot$ HCC in \%

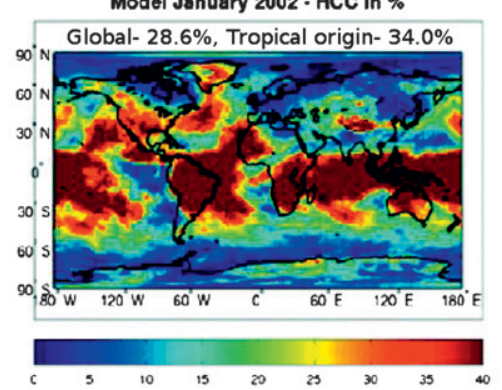

(h) Model - High cloud cover ( $\mathrm{HCC}$ )

FIG. 2. Comparison of (left) ISCCP observations and (right) model-simulated cloud cover for January 2002. The subplots show different ISCCP cloud categories [(a),(b) deep convective cloud cover, (c),(d) cirrus cloud cover, (e),(f) cirrostratus cloud cover, and (g),(h) high cloud cover]. The bold numbers on the top of figures denote the average mean values of cloud quantities computed for global region and for the regions of tropical origin $\left( \pm 50^{\circ} \mathrm{N}\right)$. The color bar represents the respective cloud fractions in percentage. Note the different color scale for deep convective cloud cover. 
TABLE 1. Global and tropical average mean values for geographical distribution of different cloud amounts from ISCCP observations and ECHAM5 model for January 2002.

\begin{tabular}{|c|c|c|c|c|}
\hline \multirow[b]{2}{*}{ Cloud amount in \% } & \multicolumn{2}{|c|}{ ISCCP observations } & \multicolumn{2}{|c|}{ Model simulation } \\
\hline & Global & Tropical origin $\left( \pm 50^{\circ} \mathrm{N}\right)$ & Global & Tropical origin $\left( \pm 50^{\circ} \mathrm{N}\right)$ \\
\hline Deep convective cloud & 3.5 & 3.6 & 4.4 & 4.9 \\
\hline Cirrus cloud & 12.5 & 13.8 & 18.1 & 21.9 \\
\hline Cirrostratus cloud & 6.2 & 6.5 & 6.1 & 7.2 \\
\hline High cloud & 22.2 & 23.9 & 28.6 & 34.0 \\
\hline
\end{tabular}

followed by detrainment of air to form thick cirrus clouds that drift with the upper-tropospheric wind, where they undergo their formation to maturation and decay during their life cycle.

Trajectories of air parcels are constructed using upper-tropospheric winds obtained from the wind fields provided by the 40-yr ECMWF Re-Analysis (ERA-40) of observations (to construct the observations-based trajectories) and model wind fields (for the model-based trajectories). Thus, the cirrus cloud evolution is tracked by keeping a record of its cloud amount at various stages along these trajectories. A similar method has been employed to study marine stratus clouds (Bretherton and Pincus 1995; Pincus et al. 1997) and upper-tropospheric humidity (Salathe and Hartmann 1997, 2000) regionally. Luo and Rossow (2004) extended this trajectory analysis to global 6-hourly ISCCP observations and ISCCP split-window cirrus data using National Centers for Environmental Prediction (NCEP)National Center for Atmospheric Research (NCAR) reanalysis wind data. Another study for the deep convection transition was by Horváth and Soden (2008) where they determined cirrus life cycle and $e$-folding times and their relation to upper-tropospheric humidity using satellite observations. In this study, we extend the analysis done by Luo and Rossow (2004) to compare the ISCCP D2 daytime observations and the ISCCP simulator cloud diagnostics from the ECHAM5-GCM simulations.

The trajectories (time evolution of air parcels originating at a defined height) are computed with the Hybrid Single-Particle Lagrangian Integrated Trajectory Model (HYSPLIT) (Draxler and Hess 1997) using gridded meteorological fields from the ERA-40 reanalysis data at a spatial resolution of $1.5^{\circ} \times 1.5^{\circ}$ and a temporal resolution of $6 \mathrm{~h}$. From this dataset, we use the threedimensional vertical distribution of wind, temperature, and relative humidity (for the HYSPLIT program initialization, later only two dimensional trajectory locations are used; see description below) together with the twodimensional wind fields at $10-\mathrm{m}$ height, temperature fields at 2-m height, and the surface geopotential to compute the ERA-40 observational trajectories of air parcels with the HYSPLIT program.
The average of the wind field over the whole air column between 500 and $200 \mathrm{hPa}$ in the reanalysis data are used to represent the mean upper-tropospheric wind. Vertical movement of air masses is not considered and the two-dimensional movement of the air columns within the 500-200-hPa layer is tracked and analyzed in this study. A similar approach was adopted for other cloud types by Pincus et al. (1997) and Salathe and Hartmann (1997). In the case of the model, the corresponding wind fields simulated by ECHAM5 are used to compute the model trajectories of air parcels with the HYSPLIT program. The trajectories are originated at a height of $7 \mathrm{~km}$ to represent the upper-tropospheric deep convective origins of trajectories within the HYSPLIT model. The twodimensional forward air trajectories are followed for a maximum of 5 days after the convective event because at the end of 5 days the air column between 500 and $200 \mathrm{hPa}$ may well have subsided into a lower level (Luo and Rossow 2004). Since the same approach is taken for both the model and the observations, this $2 \mathrm{D}$ treatment is no fundamental limitation for our conclusions.

As the HYSPLIT program provides desired temporal ( $3 \mathrm{~h}$ in our case) locations of the air parcels along the trajectories, every time an observation/model field is available, we can extract the cloud properties supplied by this field at the corresponding location of the air parcel. The cloud properties of the air parcels along each trajectory are computed via the nearest available gridbox cloud information for the respective parcel location and the observation/model output time. Following the study of Luo and Rossow (2004), the cirrus amount is used as an indicator of its life cycle and the cirrus cloud amount, and average cirrus properties ( $p_{\text {top }}$ and $\tau$ ) within each observation or model grid box are calculated for every time step. For example, for cirrus formed by convective detrainment, cirrus amount monotonically decreases (after a start-growth phase) until it vanishes (Luo and Rossow 2004).

The forward air trajectory analysis in this study is initiated by the definition of deep convective event targets. Here, these deep convective events are defined as the last grid box in a time sequence that has more than $10 \%$ of deep convective cloud cover. To assure that this 
deep convective cloud amount at an instant is the start of an event, an additional condition is imposed that the downstream grid boxes of this target trajectory consists of less deep convective cloud amount than the starting location. This additional condition ensures that the previous deep convective event ended and the rest of the deep convection seen over the trajectory path is an individual convective core independent of previous events (since it has less deep convective cloud amount in the second time step than the first over the trajectory path, signifying decay of previous deep convective event). The trajectories are considered valid only when they fulfill the criteria mentioned above or else they are discarded in the analysis. Also, as applied in their study by Luo and Rossow (2004), initiating trajectories from where the previous convective event dies out provides a way of separating cirrus formed from convective detrainment from cirrus that are dynamically formed in situ, assuring that the valid trajectories represent deep convectiongenerated cirrus. Hence, the trajectories are originated from the deep convective targets and filtered before further analysis for their transition from convection (thick anvils) to cirrostratus and subsequently to cirrus in a span of 5 days. The sampling time steps of $6 \mathrm{~h}$ for deep convective targets assures that if a forward trajectory undergoes a complete formation-mature-decay cycle of cirrus over time, the trajectory is terminated. Subsequently, a new trajectory is originated from this time step if a new deep convective event occurs, leading to a new valid trajectory that follows the new formationmature-decay cycle and so on.

Figure 3 shows examples of the forward air trajectories for two starting time steps (one in January 2002 and one in July 2002) for the ISCCP observations and the GCM output, respectively. The circles on the trajectory plots represent the starting locations for the trajectories (selected convective targets hereafter). At a level of about $7 \mathrm{~km}$ (assumed height of trajectory origin in this study), the air parcels originating from the deep convective targets tend to travel toward the subtropics. Similar to the findings by Luo and Rossow (2004), some trajectories in the winter hemisphere are carried forward by mesoscale subtropical jet streams traveling a longer distance over the 5-day period compared to the summer hemisphere trajectories. In general, the model has more convective targets than the ISCCP observations. The frequency of occurrence of deep convective targets in percentage (indicative of how often a particular location is selected as a target in a 6-h sampling time) reflects the monthly average distribution of deep convective cloud amount as seen in Fig. 2.

On average, when the model data are sampled every $6 \mathrm{~h}$ for the determination of deep convective targets, there are $\sim 1600-2000$ trajectories initialized for each sampling time step. Hence, for an overall sampling of 1 month in the model data, it comes out to be about 200000 trajectories. In the ISCCP retrievals, we find about $\sim 300-450$ convective targets per sampling time, making an overall composite of 48000 trajectories for 1 month. Part of this discrepancy is explained because in the model we sample both day and night. However, there is also an overestimation of the frequency of occurrence of deep convection in the ECHAM5 model. However, in both the model and the observations, the samples are sufficiently large to produce unbiased results for the Lagrangian analysis.

The Northern Hemisphere winter and summer analysis of the cloud trajectory origin locations (Figs. 3a-d) show no substantial seasonal difference in terms of number of deep convective targets and the corresponding trajectory paths (traveling from the tropics toward drier subtropics). Considering that the focus here involves the clouds of tropical origin within the latitudinal belt of $\pm 50^{\circ}$, further analysis of the cloud transitions is presented only for the winter month of the year 2002.

\section{a. Cloud transitions in ISCCP joint histograms}

Sequential daily average histograms are created by averaging over all the trajectories that are considered valid in the analysis for January 2002 for both the observations and the ECHAM5 model.

\section{1) ISCCP OBSERVATION HISTOGRAMS}

The forward trajectories of air parcels are followed showing the systematic changes in cloud properties over time. A clear transition of deep convective clouds to thick cirrostratus on day -1 and finally decaying to thin cirrus afterward is seen (Figs. 4a-f). At the same time, the air parcels tend to move gradually toward drier regions. The cirrostratus and thicker cirrus are found abundant closer to the deep convective regions lasting about 1 day, and gradually thin out as air advects into dry regions away from convection. In the subsequent time steps (day -2 and -3 over the Lagrangian trajectory path) after the air moves farther away from the deep convective targets, the mid- and low-level clouds become gradually more predominant.

The average cloud amounts of various categories for the 5-day transitions averaged over all the trajectories are listed in Table 2 for January 2002. The ISCCPobserved total cloud cover (TCC) drops from $97.0 \%$ in the convective source regions to $8.9 \%$ on the fifth day. The reason for this large decrease is the decay of cirrus originating from convection and the fact that most trajectories travel from the tropics to the much less cloudy subtropics and midlatitudes. The high cloud cover drops 


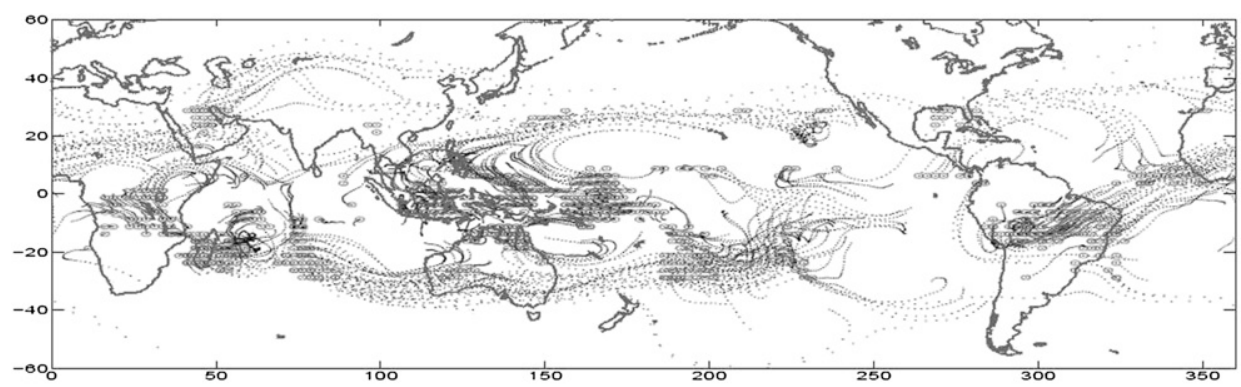

(a) ISCCP observations - January 2002

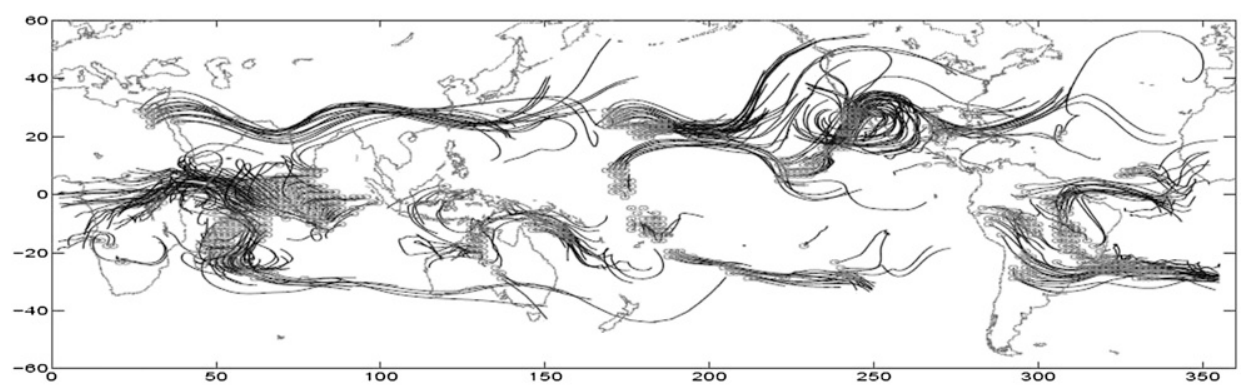

(b) ECHAM5 model - January 2002

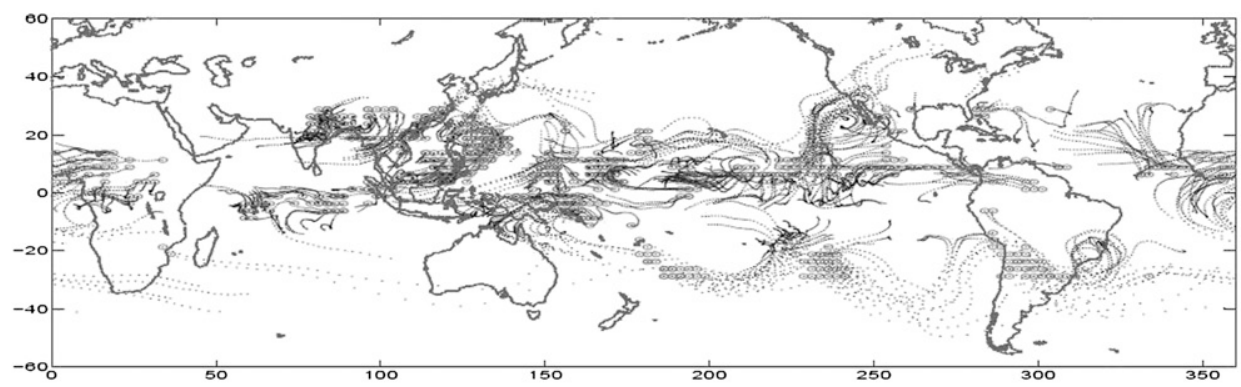

(c) ISCCP observations - July 2002

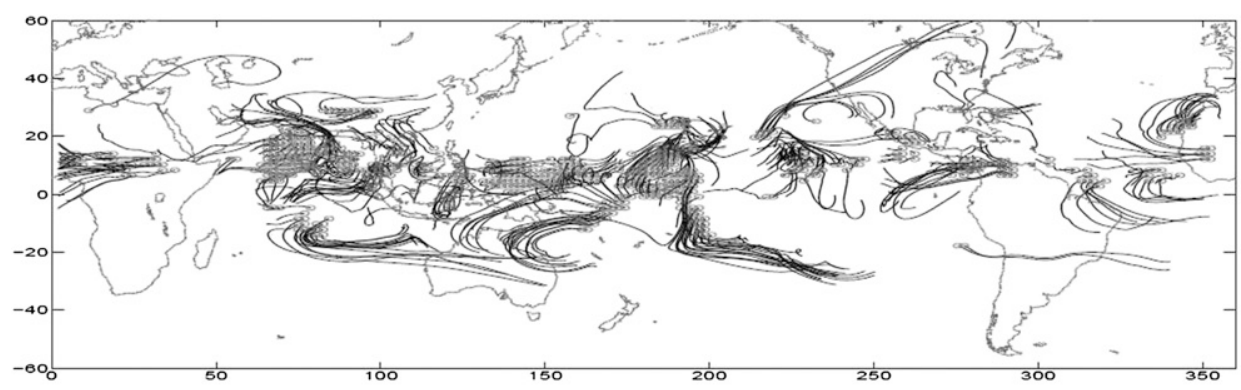

(d) ECHAM5 model - July 2002

FIG. 3. Example of tropically originating forward trajectories for ISCCP observations [showing (a) winter and (c) summer] and ECHAM5 model output [showing (b) winter and (d) summer] for the year 2002. The shown trajectories evolve from one particular sampling instance. Starting points (deep convective event targets) are shown as circles, and dots and lines show the displacement of the air parcels at 3-h intervals for observations and model, respectively. 


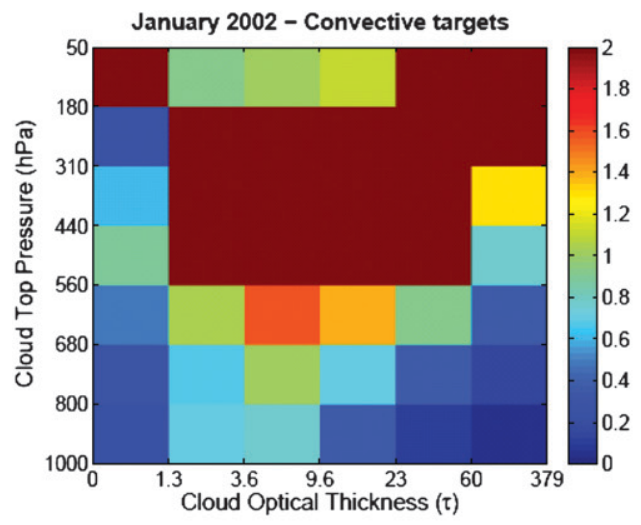

(a) Deep-convective targets

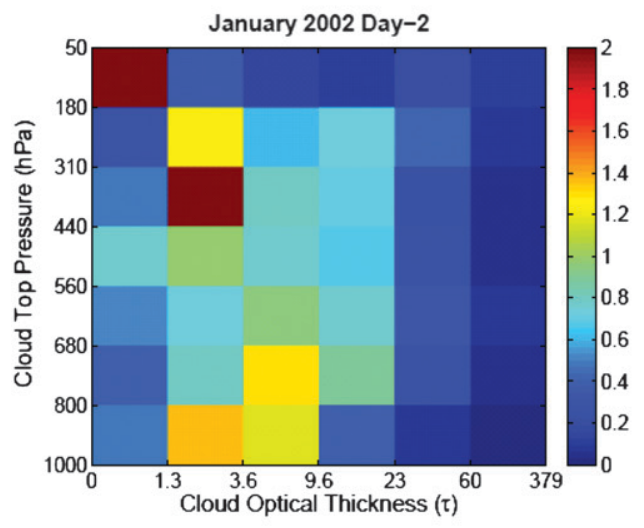

(c) Day-2 after convective event

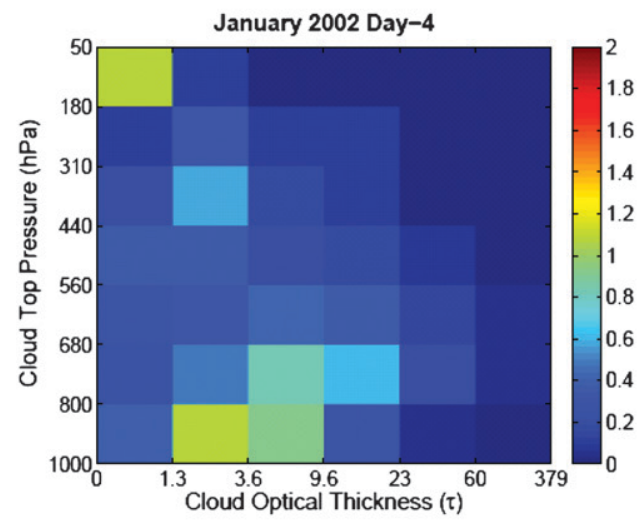

(e) Day-4 after convective event

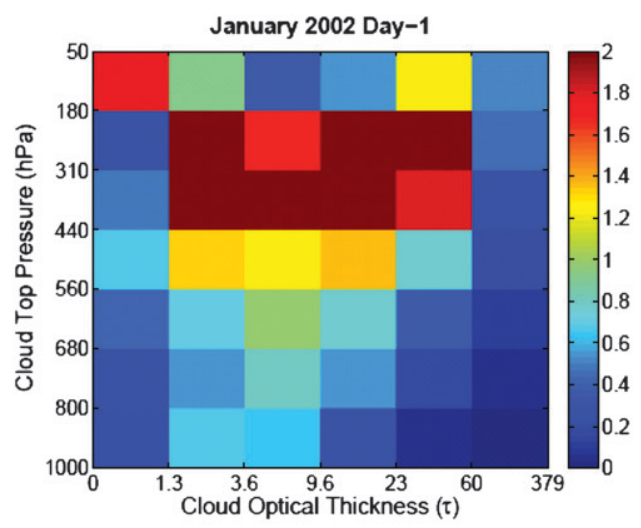

(b) Day-1 after convective event

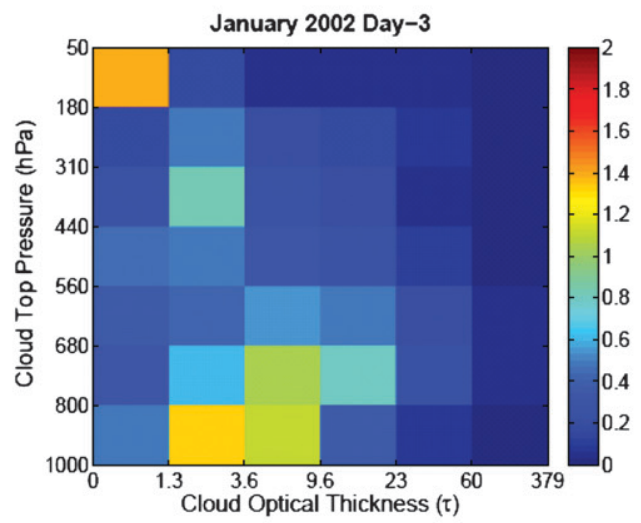

(d) Day-3 after convective event

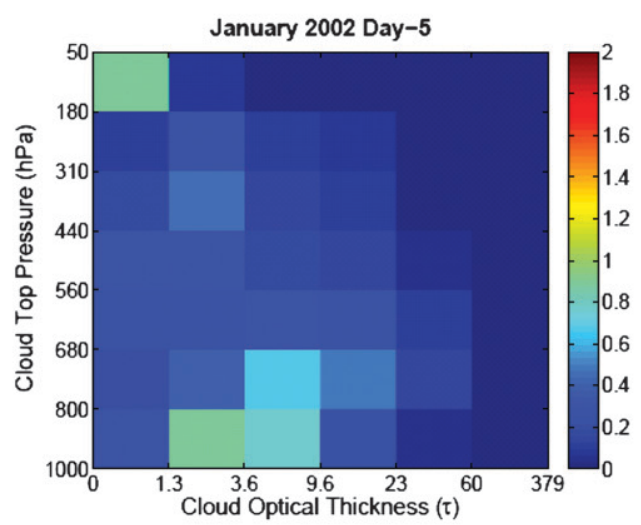

(f) Day-5 after convective event

FIG. 4. ISCCP observation Lagrangian transition histograms for January 2002. ISCCP histograms for each day are computed over averaged trajectories starting from deep convective targets and traveling for the next 5 days after the convective event. 
TABLE 2. Daily mean values of cloud amount in percentage from ISCCP observations and the ECHAM5 model for January 2002.

\begin{tabular}{|c|c|c|c|c|c|c|c|c|c|c|}
\hline \multirow{3}{*}{$\begin{array}{l}\text { Time from last } \\
\text { convection }\end{array}$} & \multicolumn{10}{|c|}{ ISCCP cloud types } \\
\hline & \multicolumn{2}{|c|}{ Total cloud } & \multicolumn{2}{|c|}{ High cloud } & \multicolumn{2}{|c|}{ Deep convective cloud } & \multicolumn{2}{|c|}{ Cirrostratus cloud } & \multicolumn{2}{|c|}{ Cirrus cloud } \\
\hline & ISCCP & ECHAM5 & ISCCP & ECHAM5 & ISCCP & ECHAM5 & ISCCP & ECHAM5 & ISCCP & ECHAM5 \\
\hline $\begin{array}{l}\text { Deep convective } \\
\text { targets }\end{array}$ & 97.0 & 99.9 & 73.3 & 90.4 & 32.3 & 52.2 & 27.5 & 31.4 & 13.4 & 6.8 \\
\hline Day-1 & 40.1 & 91.3 & 27.0 & 65.3 & 7.3 & 23.8 & 10.6 & 25.0 & 9.0 & 16.4 \\
\hline Day -2 & 24.6 & 32.0 & 10.6 & 13.1 & 1.0 & 0.8 & 3.0 & 2.5 & 6.4 & 9.7 \\
\hline Day-3 & 14.5 & 20.2 & 4.4 & 7.5 & 0.1 & 0.06 & 0.9 & 0.9 & 3.3 & 6.4 \\
\hline Day -4 & 10.9 & 15.5 & 3.0 & 6.1 & 0.1 & 0.03 & 0.5 & 0.8 & 2.3 & 5.2 \\
\hline Day-5 & 8.9 & 12.0 & 2.5 & 4.8 & 0.1 & 0.02 & 0.4 & 0.6 & 1.9 & 4.1 \\
\hline
\end{tabular}

down from $73.3 \%$ for the convective target locations to $27.0 \%$ on day -1 and finally reduces to $2.5 \%$ on the fifth day of trajectory. Also, in relative terms, the share of high clouds of the total cloud cover drops from almost $3 / 4$ to slightly more than $1 / 4$ during the transition. The deep convective cloud cover - the subset of high cloud that is optically thickest-dominates on day-1 and then reduces to a negligible $\sim 0.1 \%$ after day -2 . The behavior of cirrostratus follows the deep convective clouds with maximum value on the convective target locations (27.5\%) and gradual decrease afterward with $10.6 \%$ on day -1 to $0.4 \%$ on day -5 , but in relative terms it is most important on day -1 . The cirrus cloud cover reaches its maximum $(13.4 \%)$ on day -0 (convective target instances) following the decrease in deep convective clouds and then decreases monotonically on the rest of the days $(6.4 \%$ on day -2 to $1.9 \%$ on day-5). However, in relative terms, these optically thin high clouds become more and more important, from less than $20 \%$ to more than $75 \%$ of all high clouds. In conclusion, the HCC decreases after the convective event since the clouds evaporate and cloud particles sediment out, shifting from optically thick to thinner cloud structures. The relation between cirrus and cirrostratus growth presented here is consistent with the findings of Luo and Rossow (2004), which are discussed in detail in the upcoming section $4 \mathrm{~b}$.

\section{2) Model Output Histograms}

To compare the observation analysis to model simulations, the histogram transition plots for the ECHAM5 model output are shown in Fig. 5. As in the observations, the model histograms are created by averaging over all the valid trajectories for January 2002. Many inferences for model behavior are explored in comparison to the ISCCP observations in the following section. While new satellite observations such as the cloud radar on CloudSat (Stephens et al. 2002) offer a wealth of possibilities to further evaluate the model and such evaluation studies are indeed performed for ECHAM (e.g., Nam and Quaas 2012), we believe that much can still be learned from ISCCP observations owing to its 3-hourly temporal resolution. In general, similar to the ISCCP observations, the Lagrangian analysis shows the movement of air starting from the deep convective targets and reaching toward the drier regions or the midlatitudes (confirmed by average relative humidity model field over trajectory paths; not shown). Analyzing the trajectories in the ECHAM5 results, several interesting model deficiencies can be identified. In comparison to the ISCCP observations, the model output shows much stronger convective activity with many high thick clouds on day -0 (convective targets) and day-1 after the convective event. Almost all clouds are concentrated in the histogram section representing the upper troposphere (above $560 \mathrm{hPa}$ ), mostly with large optical thicknesses. This is in contrast to the much richer distribution seen in the satellite data, which show fewer very thick clouds but a broad spectrum of clouds with cloud tops throughout the atmospheric column and a substantial amount of clouds very high in the atmosphere. Specifically, on day-1 after the convective events, a fairly substantial overestimation in the frequency of occurrence of high thick clouds is found in the model. Thereafter, generally the model is more consistent with the observations, with a tendency to produce too-thick clouds. This result allows conclusions about deficiencies of the convection scheme in the model: in reality, a spectrum of convective clouds allows for the moisture transported from the boundary layer by convection to be distributed over much of the mid- and high troposphere. In the model, however, penetrative convection is simulated too frequently to transport too much moisture too high into the atmosphere without enough detrainment at midlevels. This moisture accumulated (inferred from the high-level cloud fields) in the upper troposphere then stays there too long before diluting, compared to the observations. A more quantitative model evaluation is given below by first analyzing the average cloud amounts and then the transition time scales.

The model-simulated cloud amounts of various categories in the average 5-day transitions over all the trajectories for the winter month for year 2002 are listed in Table 2 in comparison with the ISCCP observations. For 


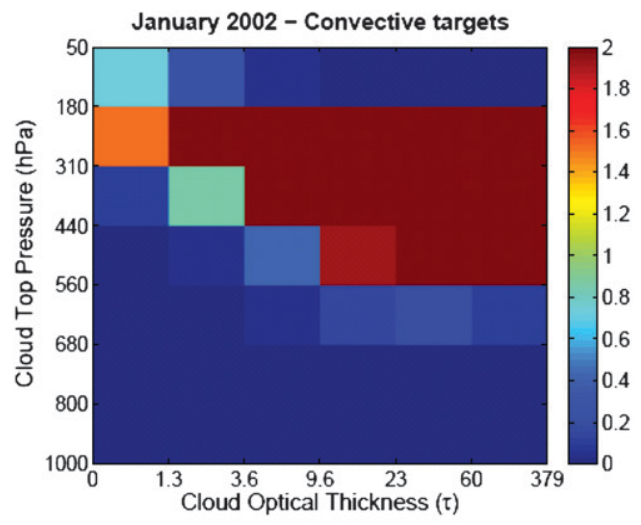

(a) Deep-convective targets

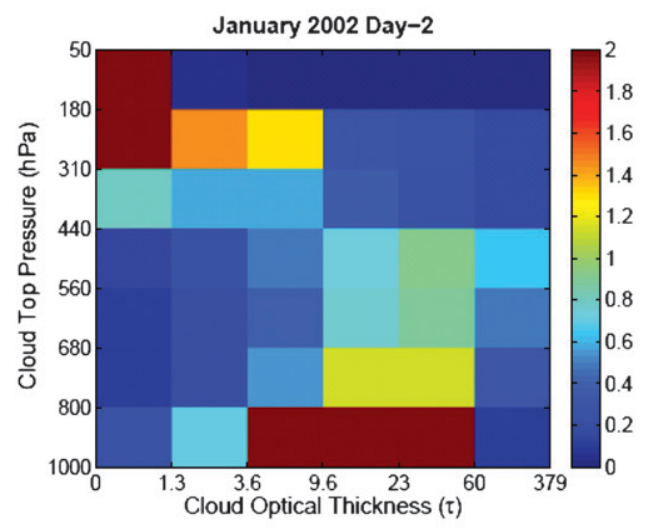

(c) Day-2 after convective event

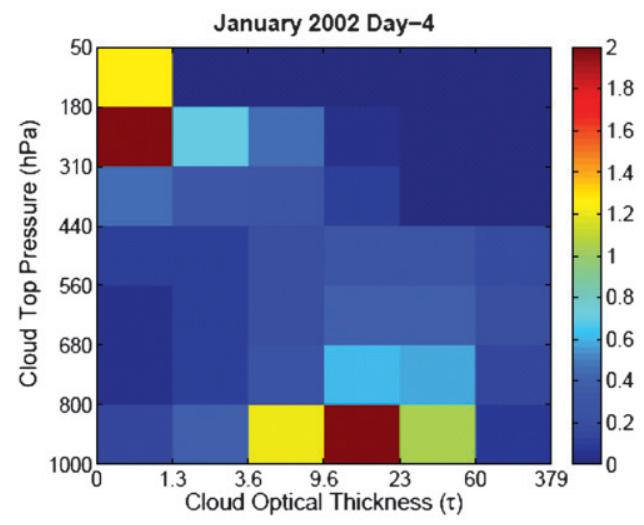

(e) Day-4 after convective event

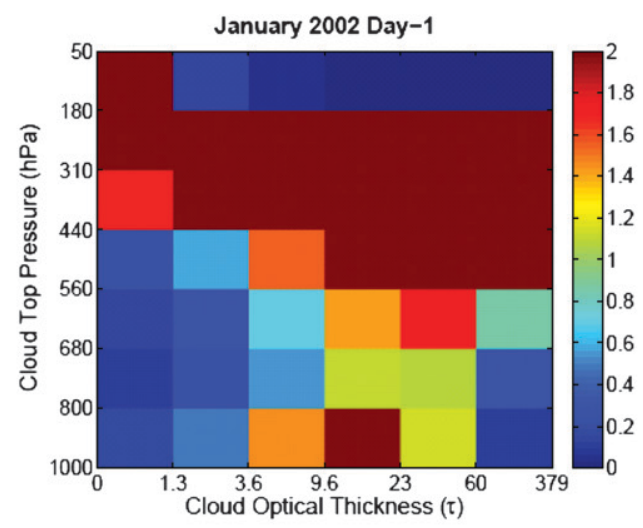

(b) Day-1 after convective event

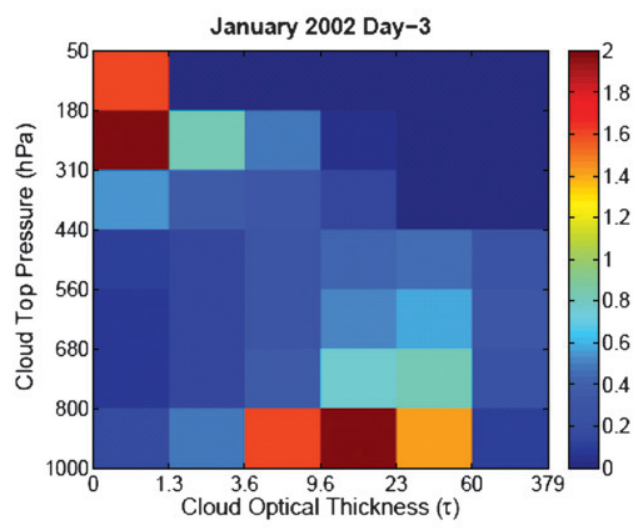

(d) Day-3 after convective event

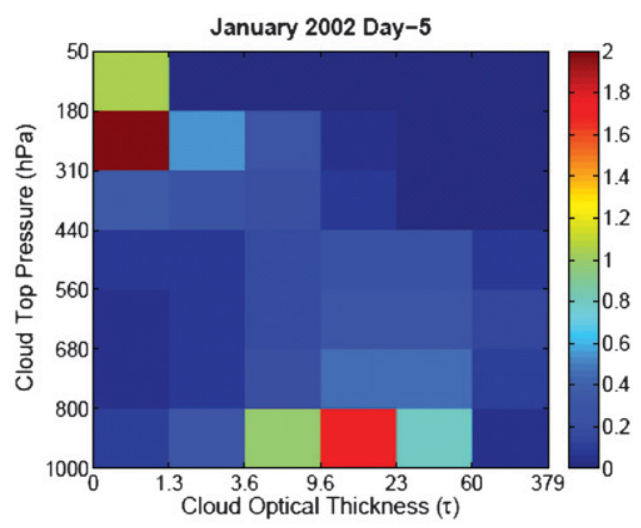

(f) Day-5 after convective event

FIG. 5. As in Fig. 4, but for an ECHAM5 simulation.

the model, the total cloud cover drops from $99.9 \%$ in the convective source regions to $12.0 \%$ on the fifth day for the winter month. Broadly, this is in agreement with the observations, except for the stark overestimation of total cloud cover on day -1 by more than a factor of 2 , and a certain overestimation also thereafter, but only by about $50 \%$. It is clear that most of this overestimation is due to too-large fractional cover by high clouds. The high cloud cover drops down from $90.4 \%$ for the convective target locations to $65.3 \%$ on day -1 and finally 


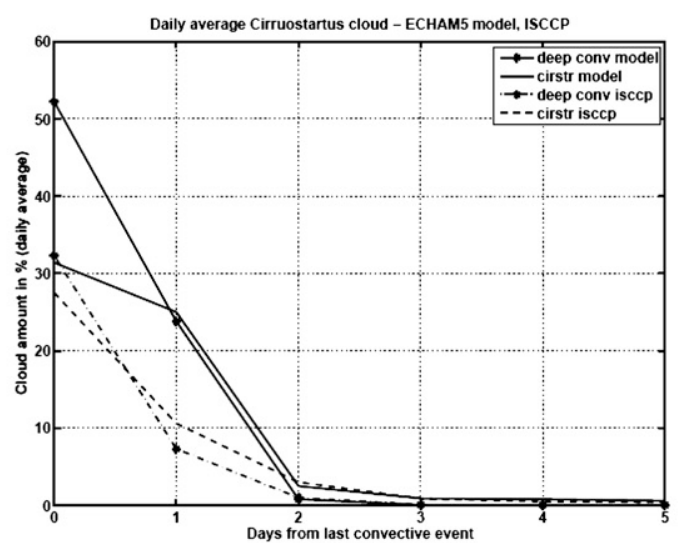

(a) Cirrostratus cloud amount

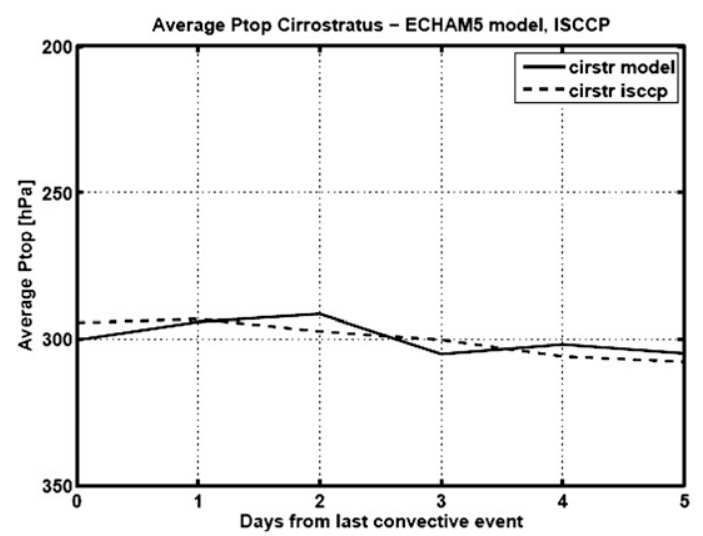

(c) Cirrostratus cloud - $p_{\text {top }}$

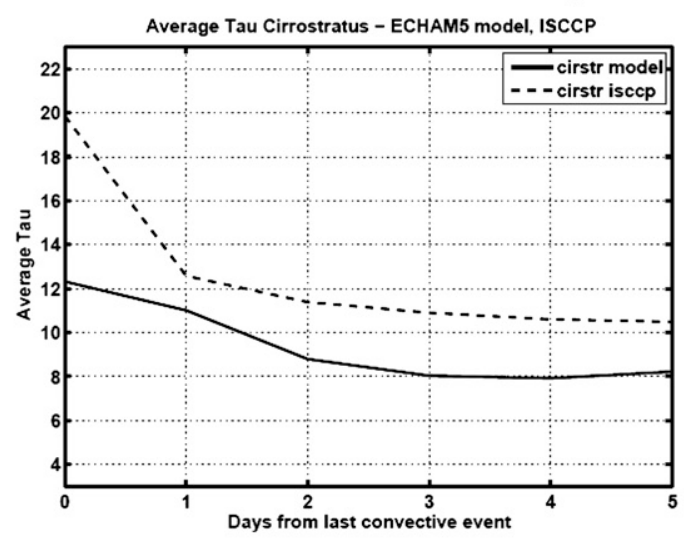

(e) Cirrostratus cloud - $\tau$

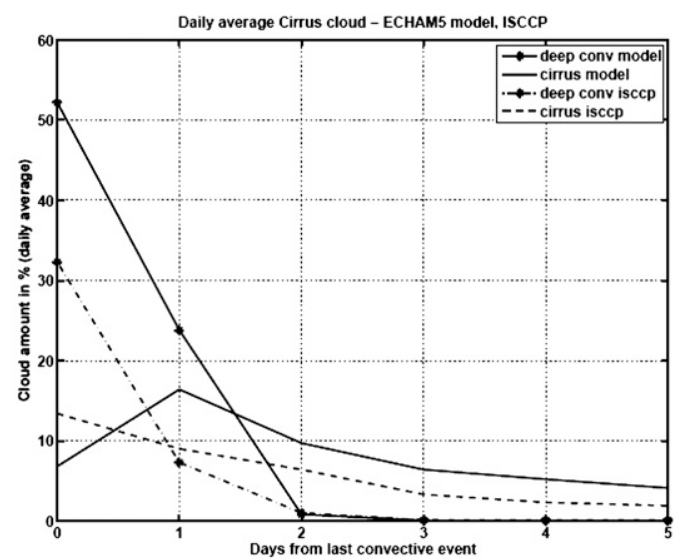

(b) Cirrus cloud amount

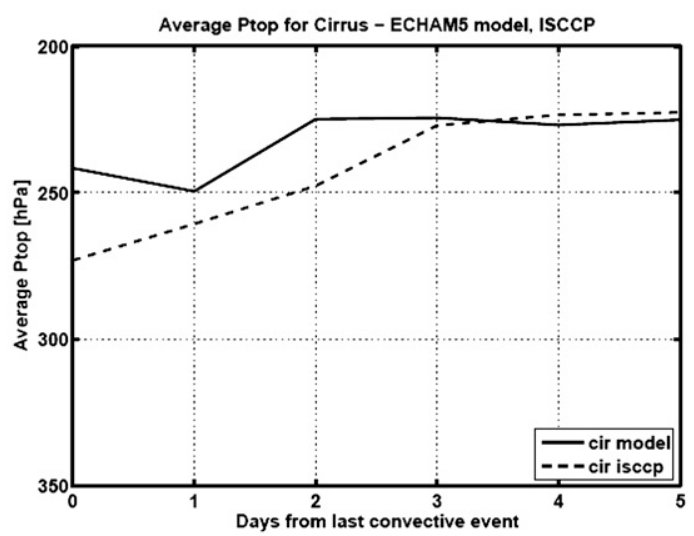

(d) Cirrus cloud - $p_{\text {top }}$

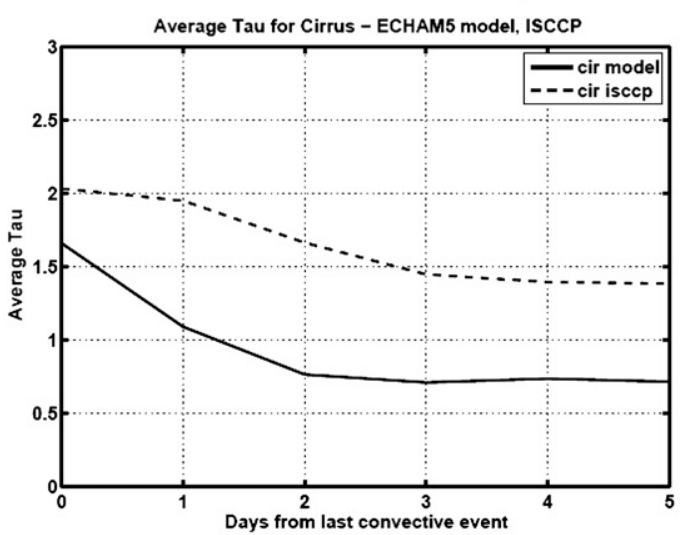

(f) Cirrus cloud - $\tau$

FIG. 6. Average cloud properties for ECHAM5 model output (solid line) compared to ISCCP observations (dashed line) for January 2002, averaged over all trajectories. Cloud type definitions are by cloud-top pressure and cloud optical thickness as defined in Fig. 1. (a) Cirrostratus and deep convective cloud amounts; (b) cirrus cloud amounts with also the deep convective cloud amount for reference. Cloud-top pressure for (c) cirrostratus clouds and (d) cirrus clouds; cloud optical thickness for (e) cirrostratus and (f) cirrus clouds. 


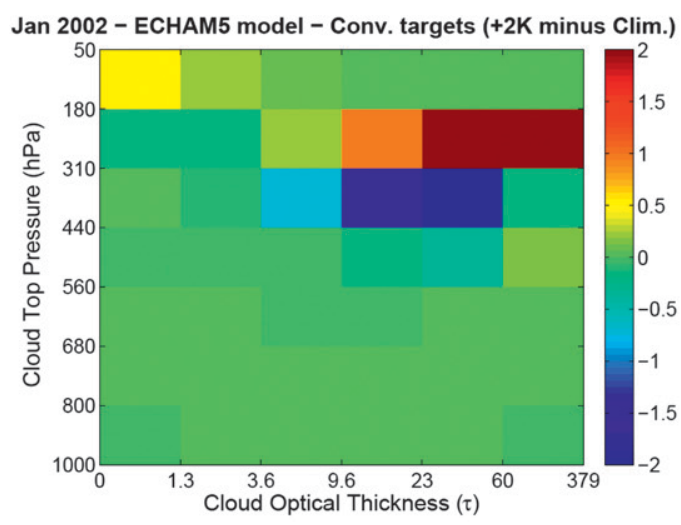

(a) Deep-convective targets

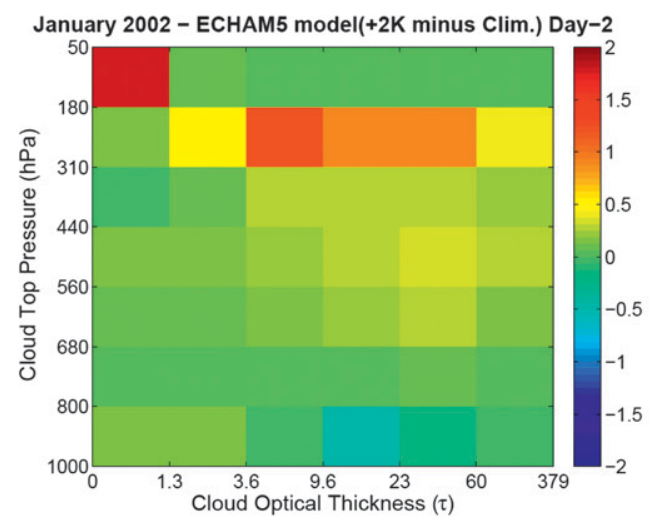

(c) Day-2 after convective event

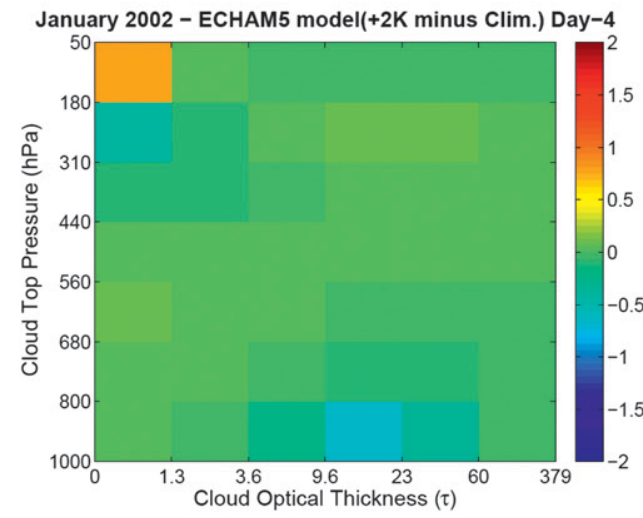

(e) Day-4 after convective event

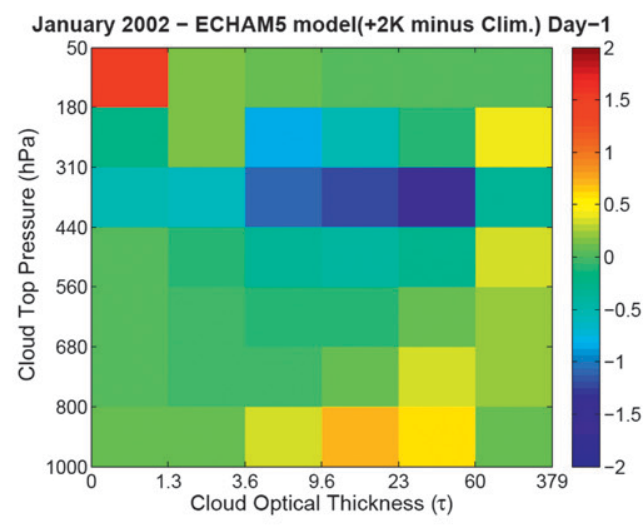

(b) Day-1 after convective event

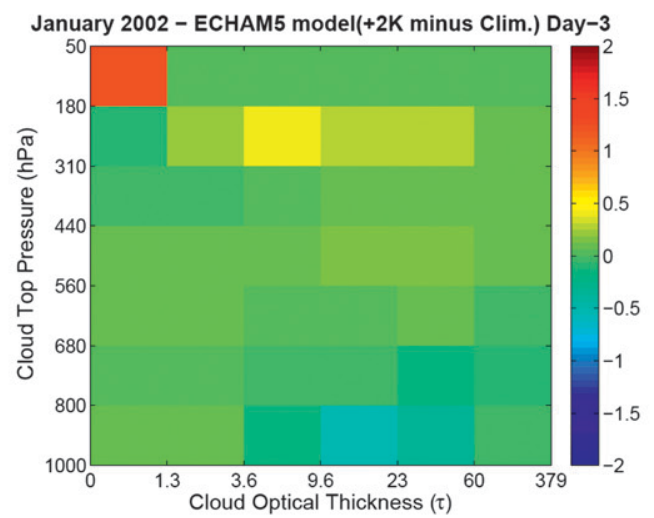

(d) Day-3 after convective event

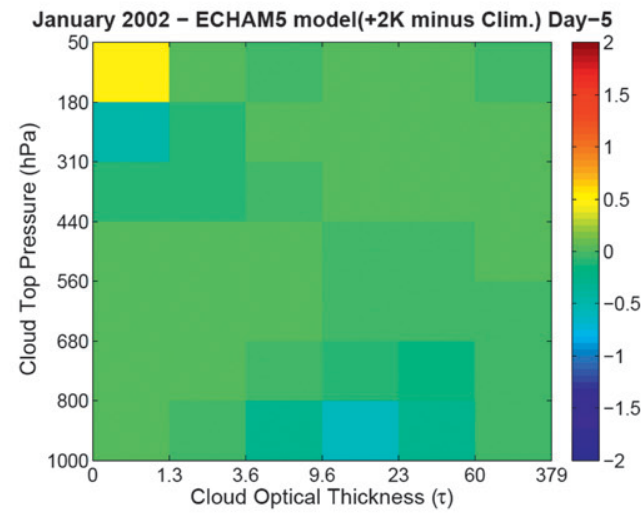

(f) Day-5 after convective event

FIG. 7. Lagrangian transition difference histograms for $+2 \mathrm{~K}$ perturbed SST model run and climatological SST run-January 2002. Simulated ISCCP histograms for each day are computed over averaged trajectories starting from deep convective targets and traveling for the next 5 days after the convective event. The color bar shows the differences (positive and negative) for histogram cloud amount in percentage.

reduces to $4.8 \%$ on the fifth day of trajectory, and is thus substantially larger than observed on all days, especially on day-1. Breaking down the high cloud cover into the optical thickness categories, the main problems can be identified. The deep convective cloud cover dominates the total cloud cover on day -1 with a share of almost $50 \%$ of the total cloudiness (compared to just $30 \%$ in the satellite observations). A substantial overestimation by a factor of 3 of the deep convective cloud cover is found on day-1. It then reduces-as in the observations- to 
TABLE 3. Daily mean values of cloud amount in percentage from perturbed SST model run—January 2002.

\begin{tabular}{|c|c|c|c|c|c|}
\hline \multirow[b]{2}{*}{ Time from last convective event } & \multicolumn{5}{|c|}{ ISCCP cloud types } \\
\hline & Total cloud & High cloud & Deep convective cloud & Cirrostratus cloud & Cirrus cloud \\
\hline Deep convective targets & 99.8 & 90.7 & 53.1 & 30.5 & 7.0 \\
\hline Day-1 & 88.4 & 60.5 & 22.1 & 21.4 & 16.9 \\
\hline Day-2 & 41.4 & 20.2 & 2.5 & 5.3 & 12.3 \\
\hline Day-3 & 22.8 & 10.2 & 0.5 & 1.8 & 7.7 \\
\hline Day -4 & 14.8 & 6.5 & 0.1 & 1.0 & 5.3 \\
\hline Day -5 & 10.3 & 4.6 & 0.0 & 0.6 & 3.9 \\
\hline
\end{tabular}

about $1 \%$ on day -2 and a negligible $\sim 0.1 \%$ thereafter. Simulated behavior of cirrostratus follows very well the observed trajectory for most of the transition, except for a clear overestimation by a factor of 2 on day -1 . The simulated cirrus cloud cover is too low compared to the observations on day -0 and reaches its maximum (16.4\%) on day -1 following the decrease in deep convective clouds. It then decreases monotonically on the rest of the days (9.7\% on day -2 to $4.1 \%$ on day -5$)$, with a certain overestimation compared to the observations by $30 \%-50 \%$ of the cloud amount.

\section{b. Variation of cirrus and cirrostratus clouds along forward trajectories}

Figure 6 shows the averaged cloud properties for deep convective, cirrostratus, and cirrus clouds as a function of time from last convection along the forward trajectories from the winter month (January 2002). A decay of thick convective clouds within about 1 day from the convective event is found in both model and observations, with a certain overestimation by the model in absolute terms. The cirrostratus decay is slower than the one for deep convective clouds, but too slow in the model compared to ISCCP, and remains almost constant at low values $(\sim 1 \%)$ from the second day onward.

Also evident is that the cirrus cloud amount initially grows in the model (day -0 to day -1 ) and becomes less abundant after day -1 . The cirrus cloud amount decreases slower in comparison to the cirrostratus cloud amount, and then remains constant at about $2 \%$ in the observations and at about $5 \%$ in the model.

The daily averaged distribution for cloud-top pressure for the cirrostratus clouds shows very consistent results for model and observations. It only very slightly varies in $p_{\text {top }}$ from $295 \mathrm{hPa}$ on day-1 to $307 \mathrm{hPa}$ on day -5 (decreases in height with time over the Lagrangian path). The cirrus behavior is quite different from cirrostratus clouds even if both of these clouds occur at similar cloud-top pressure range by definition. Along the trajectory, cirrus clouds are substantially higher in the atmosphere, and this height increases over time in both model and observations consistently (with a certain high bias in the model in the earlier days). Hence, with time, the cirrus clouds move to higher levels in height whereas cirrostratus clouds move toward slightly lower height levels in the ISCCP observations.

The cloud optical thickness $(\tau)$ for both cirrostratus and cirrus clouds gradually decreases over time in the observations as well as in the model. This trend is consistent with the cloud decay discussed above. The clouds remain thick and high on day -1 of the trajectory and then cloud $\tau$ decreases as the clouds thin out and move to higher levels over the next days. The apparent bias in the model in terms of cloud optical thickness for cirrostratus as well as cirrus clouds might as well be due to fewer (optically relatively thick) low-level boundary layer clouds underlying these high-level clouds diagnosed in the model in comparison with the ISCCP observations, recalling that the passive instrument, and the ISCCP simulator, diagnose only one integral cloud optical thickness.

Cirrostratus being at a higher pressure (lower level) than cirrus clouds implies that the transition from cirrostratus to cirrus is accompanied by a gradual increase in cloud-top height. The evolution of cirrus properties also indicates that cirrus clouds tend to thin out as the air moves away from convective regions. The cirrus thin out with time and rise in height because of heating while moving over regions of less lower-level cloud cover.

The Lagrangian trajectory analysis for the model output as well as the ISCCP observations show the general behavior of deep convection-cirrus interaction in the upper troposphere. As confirmed by the variations in ISCCP cloud property histograms of observations and ECHAM5 model, the decay of deep convection clouds is followed by the formation of cirrostratus and cirrus clouds. Subsequently, the cirrostratus clouds gradually decay over the next 2 days and finally the cirrus clouds thin out and evaporate over the next $2-3$ days.

\section{Cirrus clouds in a warmer climate}

Despite the model deficiencies identified above, it is interesting to investigate the behavior of high clouds originating from convection in a changing climate. To 


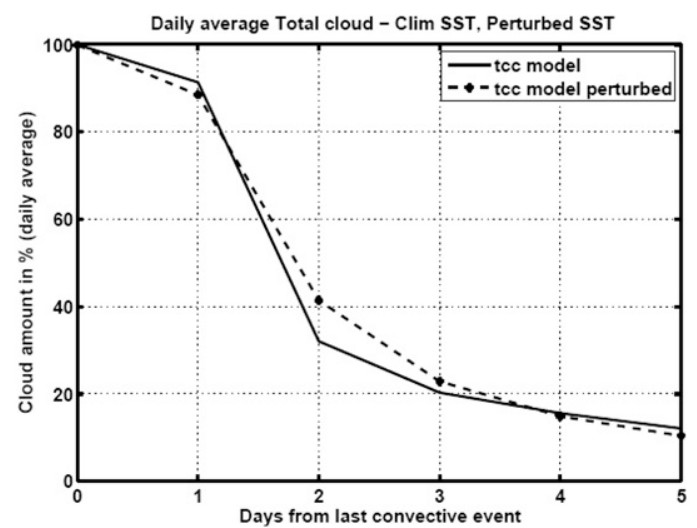

(a) Total cloud amount

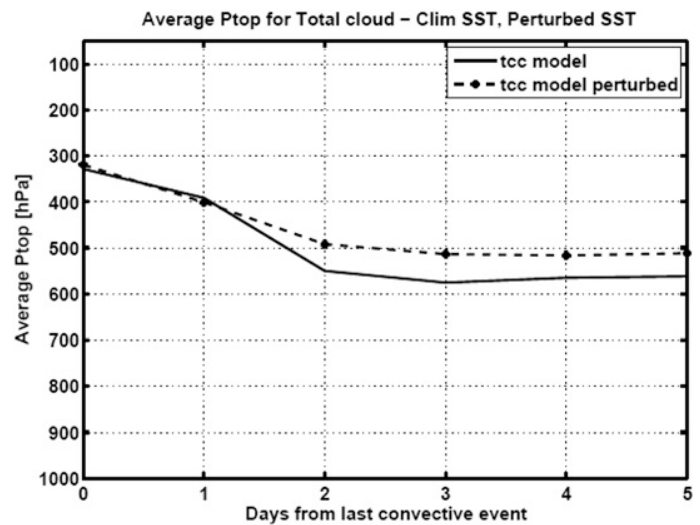

(c) Total cloud $p_{\text {top }}$

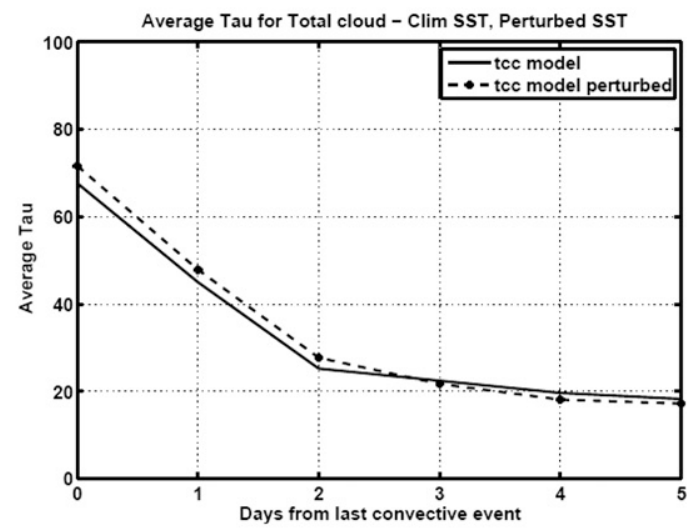

(e) Total cloud $\tau$

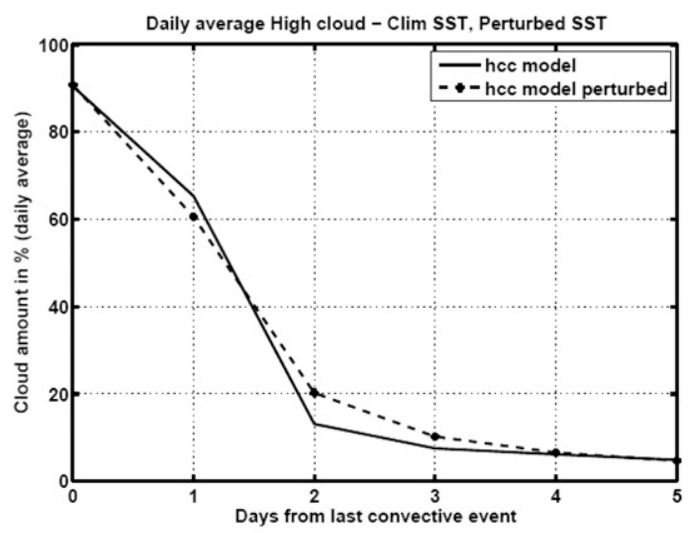

(b) High cloud amount

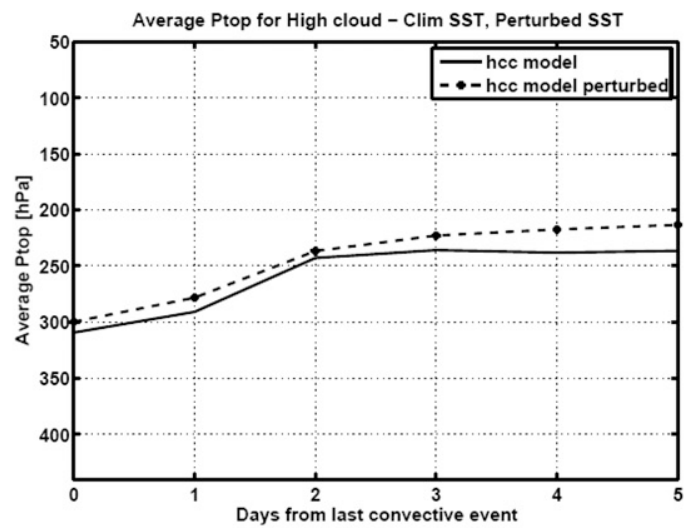

(d) High cloud $p_{\text {top }}$

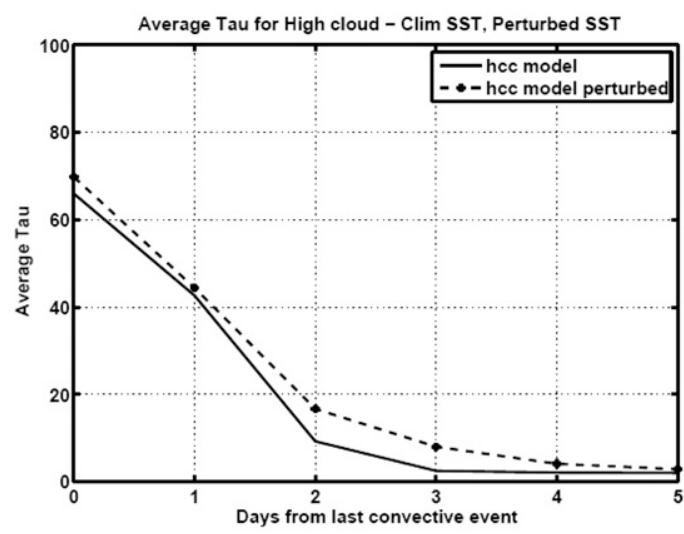

(f) High cloud $\tau$

FIG. 8. Comparison of average cloud properties for TCC and HCC for the present-day ECHAM5 model output compared to the warmer climate run (perturbed SST) — January 2002. The present-day model is shown in solid and perturbed climate in dashed line for all the subfigures.

evaluate the model sensitivity in terms of cloud transitions, an idealized climate change simulation with SSTs increased by a uniform $2 \mathrm{~K}$ (Cess et al. 1990) is performed. The other model conditions remain similar to the present-day model run with climatological SST and a spinup run for 2 years.

The Lagrangian trajectories for the perturbed model runs are created using the model wind fields within the 


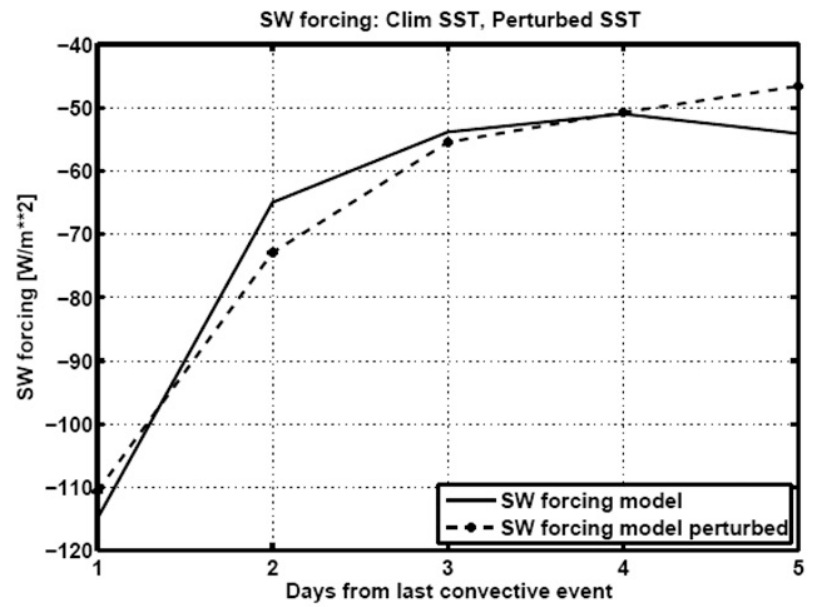

(a) SW forcing

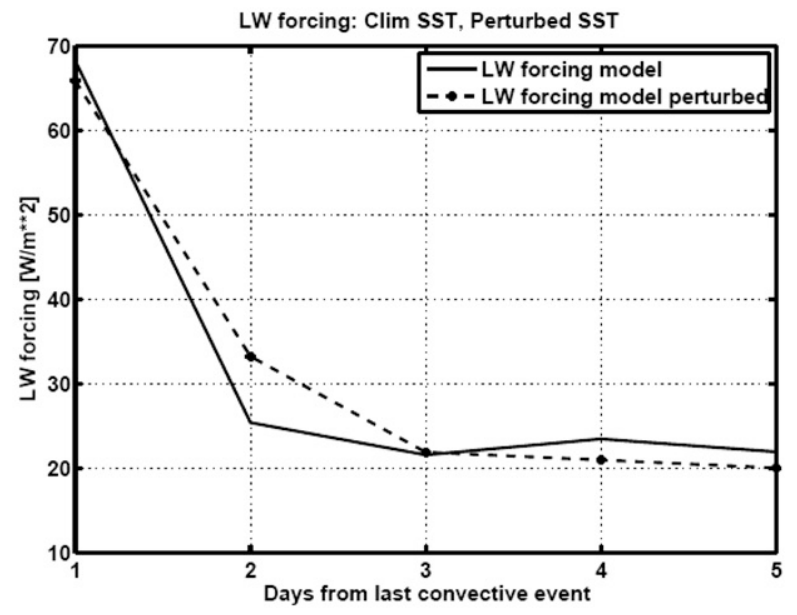

(b) LW forcing

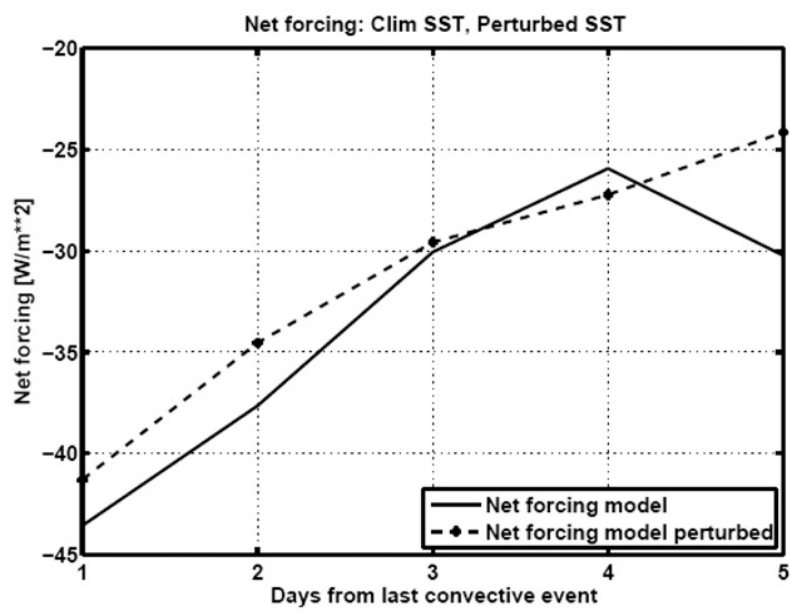

(c) Net forcing $(\mathrm{SW}+\mathrm{LW})$
HYSPLIT model (procedure explained in detail in section 4). The difference of daily average Lagrangian transition histograms of $+2 \mathrm{~K}$ perturbed SST model run with the climatological SST run (perturbed climate minus presentday climate) are shown in Fig. 7 for the convective target locations and 5 subsequent days after the convective event. As seen in Fig. 7, the high-level clouds show a significant change (increment in the warmer climate) in comparison to mid- and low-level clouds, especially on day -2 and -3 after the deep convective event.

For quantification of transition histograms for the perturbed climate runs, the daily averaged histogram values are listed in Table 3. In comparison to the present-day simulations (climatological SST runs; Table 2), the daily average values of high cloud amount in the warmer climate are slightly larger, especially on day -2 and -3 .

The ISCCP histograms of the cloud transitions in the perturbed climate model run show a discernible increment in the amount of high clouds in all categories of optical thickness on day-2 in comparison to the presentday model runs with climatological SST and still some increase in cirrostratus and cirrus amounts on day-3. As shown in Table 2 and Table 3 for daily average cloud amounts, the first and last two days, on the other hand, show little difference.

Figure 8 shows the daily average cloud properties for the total cloud cover and the high cloud cover over the Lagrangian trajectories. Total cloud amount is larger in the warmer climate along the trajectories on day-2 and -3 , and this difference is due to a larger amount of high clouds. Cloud tops for high clouds are-as expectedhigher in the warmer climate, but along the trajectories, there is an additional gradual shift in altitude, also reflected in the average cloud-top pressure for all clouds. Clouds are on average optically thicker in the perturbed climate close to the convective centers. Analyzing specifically the high clouds, we find that these are thicker along the entire trajectory, but specifically on days -2 and -3 . Investigating the clouds by categories of optical thickness, we find that the increase in altitude (decrease in cloud-top pressure) is found for all high clouds. The increase in cloud amount and cloud optical thickness, however, is mostly due to cirrostratus and deep

FIG. 9. Model cloud forcings [i.e., (a) shortwave cloud radiative effect, (b) longwave cloud radiative effect, and (c) net cloud radiative effect] for present-day ECHAM5 model (climatological SST) compared to the warmer climate run (perturbed SST) for January 2002. The present-day model is shown in solid and perturbed climate in dashed line for all the subfigures. 
convective clouds, with thinner cirrus clouds remaining similar to the unperturbed conditions. In conclusion, in a warmer climate, convection transports even more moisture to the upper troposphere, generating thicker clouds even higher in the atmosphere. The lifetime of these clouds is increased, and the thick cirrostratus and deep convective clouds last up to 2 days longer.

This implies a feedback on radiation, which is shown in Fig. 9. Especially on days -2 and -3 , the larger cloud fraction and larger optical thickness lead to a stronger negative shortwave cloud radiative effect but also to an enhanced longwave cloud effect. As shown in Fig. 7, the significant change in cloud radiative effect is attributed to the changes in high-level clouds (especially within day -1 to day -3 ). In the net, the overall cloud radiative effect is less negative over most of the transition, with a difference of about $+2 \mathrm{~W} \mathrm{~m}^{-2}$.

\section{Summary and conclusions}

An evaluation of clouds originating from deep convection as simulated by the ECHAM5 GCM using ISCCP satellite data are presented.

Clouds are classified according to the ISCCP histogram. The focus here is on high clouds with cloud-top pressures above $440 \mathrm{hPa}$. These high clouds are further divided into subcategories according to optical thickness, where thin clouds are called "cirrus" $(0 \leq \tau \leq 3.6)$, clouds with moderate optical thickness "cirrostratus" $(3.6 \leq \tau \leq$ $23)$, and thick clouds "deep convective" $(\tau>23)$.

We find that the model simulates the average geographical patterns of high clouds of all three optical thickness categories relatively well, with a certain overestimation of the thin cirrus clouds. The deep convective clouds overly prefer tropical land in the model simulations in comparison to the observations. However, a more process-oriented analysis reveals substantial model deficiencies when tracking the origin and evolution of these types of clouds. The Lagrangian trajectory analysis over 5 consecutive days after deep convective events shows a gradual decrease in high cloud cover and optical thickness, which the model broadly captures. However, the model convection is found to be too strong in a sense that too many too-thick deep convective and cirrostratus clouds are generated compared to the ISCCP observations at the expense of more clouds with lower optical thicknesses and a broader range of cloud tops also in the middle troposphere. These high clouds continue to persist for a too-long duration after 1 day, and about $50 \%$ of the deep convective cloud amount on convective targets remains on day -1 (compared to only $25 \%$ in the observations). We conclude that the convective scheme transports too much water into the upper troposphere to form too many, too-thick, and too-high clouds. Hence, the convective clouds not only have too large a cloud amount, but they also have too-large lifetimes in the ECHAM5 model compared to the ISCCP observations.

To investigate processes of the feedback of these convective clouds to climate change, an idealized simulation experiment was carried out with a uniform $+2 \mathrm{~K}$ SST warming. The changes in the convective cloud transitions for these idealized climate warming experiments show that the amount and optical thickness of high clouds increases in the warmer climate particularly on day -2 and -3 after the convection, which is indicative of a prolonged lifetime of clouds originating from convection. The model cloud diagnostics from the ISCCP simulator suggest that the high clouds tend to be higher in the atmosphere in the perturbed SST model run. Since the high cloud amount increases and moves higher in the atmosphere in the perturbed climate, it implies an increased longwave cloud radiative effect, which is found to be more prominent than the increased shortwave effect (because of slight changes in cloud optical thickness). This leads to less cooling or a positive feedback from convective detrainment in the warmer climate.

Acknowledgments. This study constitutes a part of the Ph.D. thesis of Swati Gehlot submitted at the University of Hamburg, Germany, in 2010. The International Max Planck Research School-Earth System Modeling (IMPRSESM) at the Max Planck Institute for Meteorology, Hamburg, and the German Research Foundation (Deutsche Forschungsgemeinschaft, DFG, in an Emmy Noether Grant) provided the financial support for this work. The authors thank Ákos Horváth for useful suggestions on the manuscript and Petri Räisänen for his providing the subcolumn sampler code used in the ISCCP simulator. Computing time was provided by the German Climate Computing Center (DKRZ).

\section{REFERENCES}

Ackerman, T. P., K. N. Liou, F. P. J. Valero, and L. Pfister, 1988: Heating rates in tropical anvils. J. Atmos. Sci., 45, 1606-1623.

Arakawa, A., 1975: Modelling clouds and cloud processes for use in climate models. The Physical Basis of Climate and Climate Modelling, GARP Publications Series, Vol. 16, ICSU/WMO, 181-197.

Bony, S., and Coauthors, 2006: How well do we understand and evaluate climate change feedback processes? J. Climate, 19, 3445-3482.

Bretherton, C. S., and R. Pincus, 1995: Cloudiness and marine boundary layer dynamics in the ASTEX Lagrangian experiments. Part I: Synoptic setting and vertical structure. J. Atmos. Sci., 52, 2707-2723.

Cess, R. D., and Coauthors, 1990: Intercomparison and interpretation of climate feedback processes in 19 atmospheric general circulation models. J. Geophys. Res., 95 (D10), 16 601-16 615. 
Chou, C., and J. D. Neelin, 1999: Cirrus detrainment-temperature feedback. Geophys. Res. Lett., 26, 1295-1298.

Colman, R., 2003: A comparison of climate feedbacks in general circulation models. Climate Dyn., 20, 865-873.

Draxler, R. R., and G. D. Hess, 1997: Description of the HYSPLIT_4 modeling system. NOAA Tech. Memo. ERL ARL-224, 24 pp. [Available online at http://www.arl.noaa.gov/HYSPLIT_info.php.]

Garrett, T. J., and Coauthors, 2005: Evolution of a Florida cirrus anvil. J. Atmos. Sci., 62, 2352-2372.

Hartmann, D. L., and M. L. Michelsen, 1993: Large-scale effects on the regulation of tropical sea surface temperature. J. Climate, 6, 2049-2062.

Horváth, A., and B. J. Soden, 2008: Lagrangian diagnostics of tropical deep convection and its effect upon upper-tropospheric humidity. J. Climate, 21, 1013-1028.

Klein, S., and C. Jacob, 1999: Validation and sensitivities of frontal clouds simulated by the ECMWF model. Mon. Wea. Rev., 127, 2514-2531.

Liou, K.-N., 1986: Influence of cirrus clouds on weather and climate processes: A global perspective. Mon. Wea. Rev., 114, 11671199.

Lohmann, U., and E. Roeckner, 1996: Design and performance of a new cloud microphysics scheme developed for the ECHAM4 general circulation model. Climate Dyn., 12, 557-572.

Luo, Z., and W. B. Rossow, 2004: Characterizing tropical cirrus life cycle, evolution, and interaction with upper-tropospheric water vapor using Lagrangian trajectory analysis of satellite observations. J. Climate, 17, 4541-4563.

Mace, G. G., M. Deng, B. Soden, and E. Zipser, 2006: Association of tropical cirrus in the $10-15-\mathrm{km}$ layer with deep convective sources: An observational study combining millimeter radar data and satellite-derived trajectories. J. Atmos. Sci., 63, 480503.

Machado, L. A. T., and W. B. Rossow, 1993: Structural characteristics and radiative properties of tropical cloud clusters. Mon. Wea. Rev., 121, 3234-3260.

Massie, S., A. Gettelman, W. Randel, and D. Baumgardener, 2002: Distribution of tropical cirrus in relation to convection. J. Geophys. Res., 107, 4591, doi:10.1029/2001JD001293.

May, P., J. H. Mather, G. Vaughan, C. Jakob, G. M. McFarquhar, K. N. Bower, and G. G. Mace, 2008: The Tropical Warm Pool International Cloud Experiment. Bull. Amer. Meteor. Soc., 89, 629-645.

Nam, C. C. W., and J. Quaas, 2012: Evaluation of clouds and precipitation in the ECHAM5 general circulation model using CALIPSO and CloudSat satellite data. J. Climate, 25, 49754992.

Nordeng, T. E., 1994: Extended versions of the convective parameterization scheme at ECMWF and their impact on the mean and transient activity of the model in the tropics. European Centre for Medium-Range Weather Forecasts Tech. Memo. 206, 41 pp.

Pfister, L., and Coauthors, 2001: Aircraft observations of thin cirrus clouds near the tropical tropopause. J. Geophys. Res., 106 (D9), 9765-9786.

Pincus, R., M. B. Baker, and C. S. Bretherton, 1997: What controls stratocumulus radiative properties? Lagrangian observations of cloud evolution. J. Atmos. Sci., 54, 2215-2236.

Räisänen, P., H. W. Barker, M. F. Khairoutdinov, and D. A. Randall, 2004: Stochastic generation of subgrid-scale cloudy columns for large-scale models. Quart. J. Roy. Meteor. Soc., 130, 2047-2067.
Roeckner, E., and Coauthors, 2003: The atmospheric general circulation model ECHAM5: Part I: Model description. Max Planck Institute for Meteorology Rep. 349, 127 pp.

Rossow, W. B., and R. A. Schiffer, 1991: ISCCP cloud data products. Bull. Amer. Meteor. Soc., 72, 2-20.

- and L. Garder, 1993: Cloud detection using satellite measurements of infrared and visible radiances for ISCCP. J. Climate, 6, 2391-2369.

— from ISCCP. Bull. Amer. Meteor. Soc., 80, 2261-2288.

—, A. W. Walker, D. E. Beuschel, and M. D. Roiter, 1996: International Satellite Cloud Climatology Project (ISCCP): Documentation of new cloud datasets. World Meteorological Organization Tech. Doc. WMO/TD 737, 115 pp.

Salathe, E. P., and D. L. Hartmann, 1997: A trajectory analysis of tropical upper-tropospheric moisture and convection. J. Climate, 10, 2533-2547.

— and —, 2000: Subsidence and upper-tropospheric drying along trajectories in a general circulation model. J. Climate, 13, 257-263.

Schiffer, R. A., and W. B. Rossow, 1983: The International Satellite Cloud Climatology Project (ISCCP): The first project of the World Climate Research Programme. Bull. Amer. Meteor. Soc., 64, 779-784.

Schneider, S., 1972: Cloudiness as a global climatic feedback mechanism: The effects on radiation balance and surface temperatures of variations in cloudiness. J. Atmos. Sci., 29, 1413-1422.

Senior, C. A., and J. F. B. Mitchell, 1993: Carbon dioxide and climate: The impact of cloud parameterization. J. Climate, 6, 393-418.

Soden, B. J., 1998: Tracking upper tropospheric water vapor radiances: A satellite perspective. J. Geophys. Res., 103D, 17 06917081.

2004: The impact of tropical convection and cirrus on upper tropospheric humidity: A Lagrangian analysis of satellite measurements. Geophys. Res. Lett., 31, L20104, doi:10.1029/ 2004GL020980.

Solomon, S., D. Qin, M. Manning, M. Marquis, K. Averyt, M. M. B. Tignor, H. L. Miller Jr., and Z. Chen, Eds., 2007: Climate Change 2007: The Physical Science Basis. Cambridge University Press, $996 \mathrm{pp}$.

Stephens, G. L., 2005: Cloud feedbacks in the climate system: A critical review. J. Climate, 18, 237-273.

— S. Tsay, P. W. Stackhouse Jr., and P. J. Flatau, 1990: The relevance of the microphysical and radiative properties of cirrus clouds to climate and climate feedback. J. Atmos. Sci., 47, 1742-1753.

— , and Coauthors, 2002: The CloudSat mission and the A-train: A new dimension of space-based observations of clouds and precipitation. Bull. Amer. Meteor. Soc., 83, 1771-1790.

Stubenrauch, C. J., A. Chédin, G. Rädel, N. A. Scott, and S. Serrar, 2006: Cloud properties and their seasonal and diurnal variability from TOVS Path-B. J. Climate, 19, 5531-5553.

Tiedtke, M., 1989: A comprehensive mass-flux scheme for cumulus parameterization in large-scale models. Mon. Wea. Rev., 117, $1779-1800$

Tompkins, A., 2002: A prognostic parameterization for the subgridscale variability of water vapor and clouds in large-scale models and its use to diagnose cloud cover. J. Atmos. Sci., 59, 1917-1942.

Yao, M.-S., and A. D. D. Genio, 1999: Effects of cloud parameterization on the simulation of climate changes in the GISS GCM. J. Climate, 12, 761-779. 